\title{
Synergic Transformation of an Ethylenediamine to a Lithium 1, 3-Diaza-2- zincacyclopentene via an Alkyllithium/Bis(alkyl)zinc Mixture
}

\author{
Ross Campbell, Pablo García-Álvarez,* Alan R. Kennedy, and Robert E. Mulvey*ª]
}

\begin{abstract}
Alkali metal zincates are among an increasing number of mixedmetal organoreagents that are attracting widespread attention because of their ability to exhibit synergic reactivity. Such special behaviour can be defined as reactions arising from the cooperative effects of the two distinct metals, the hard alkali metal and soft zinc, within the multicomponent zincate that cannot be reproduced by either single alkali metal or zinc component on its own. This synergism has been particularly prominent in metalation (metal-hydrogen exchange) applications. ${ }^{[1]}$ Alkylzinc $\left(\mathrm{R}_{2} \mathrm{Zn}\right)$ or amidozinc $\left[\mathrm{RZn}\left(\mathrm{NR}_{2}^{\prime}\right) / \mathrm{Zn}\left(\mathrm{NR}_{2}\right)_{2}\right]$ reagents are generally notoriously poor kinetic bases incapable of directly metalating (zincating) aromatic substrates to any synthetically useful extent, but combined with an alkali metal compound ${ }^{[2]}$ or related component ${ }^{[3]}$ they can transform into highly reactive "zincators". Kondo and Uchiyama's "LiZn(TMP) $t \mathrm{Bu}_{2}$ " (TMP = 2,2,6,6-tetramethylpiperidide), Mongin's "LiZn(TMP) $)_{3}$, , ${ }^{[2 a-j]}$ and our own [(TMEDA) Na(TMP) $(t \mathrm{Bu}) \mathrm{Zn}(t \mathrm{Bu})]^{[2 \mathrm{p}-\mathrm{t}]} \quad(\mathrm{TMEDA}=$ $N, N, N$, $N$ '-tetramethylethylenediamine) belong in this category and although fundamental differences exist between these powerful amide-based zincators, their $\mathrm{Zn}-\mathrm{H}$ exchange reactions can be grouped together as alkali-metal-mediated zincations "AMMZn's". [1] Exemplified by TMP, the amide components involved in $\mathrm{AMM} Z n$ chemistry are invariably monoanionic ligands derived from secondary amines containing one acidic $\mathrm{N}-H$ bond. Secondary diamines containing two acidic $\mathrm{N}-H$ bonds and therefore having potentially at least two metalation sites would offer an interesting contrast but until this work they have not been investigated in this context. Reported herein, our first venture in introducing diamines to this chemistry by reacting a mixture of $n \mathrm{BuLi}$ and $t \mathrm{Bu}_{2} \mathrm{Zn}$ (or $\mathrm{Me}_{2} \mathrm{Zn}$ ) with $N, N^{\prime}-$ diisopropylethylenediamine $i \operatorname{PrN}(\mathrm{H}) \mathrm{CH}_{2} \mathrm{CH}_{2} \mathrm{~N}(\mathrm{H}) i \mathrm{Pr}$ has uncovered a surprising new synergic chemistry which leads ultimately to the transformation of the saturated ethylenediamine to a dianionic unsaturated diazaethene.
\end{abstract}

[a] R. Campbell, Dr P. García-Álvarez, Dr A. R. Kennedy, Prof R. E. Mulvey WestCHEM, Department of Pure and Applied Chemistry

University of Strathclyde

Glasgow G1 1XL (UK)

Fax: (+)44 141-548 4822

E-mail: r.e.mulvey@strath.ac.uk

Supporting information for this article is available on the WWW under http://www.chemeurj.org/ or from the author.

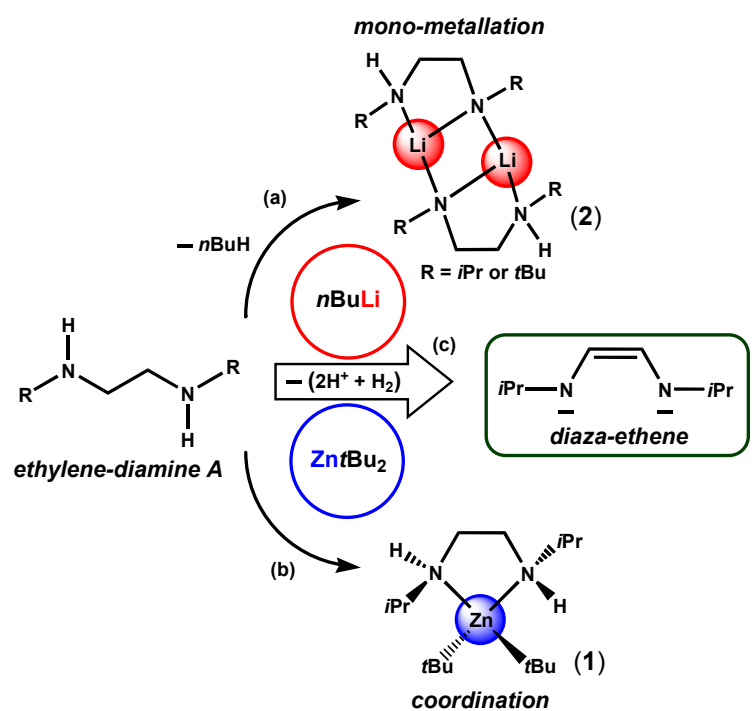

Scheme 1. Comparison of non-cooperative reactions $\left[n \mathrm{BuLi}\right.$, (a) or $t \mathrm{Bu}_{2} \mathrm{Zn}$, (b)] and cooperative reactions $\left[n \mathrm{BuLi}\right.$ and $t \mathrm{Bu}_{2} \mathrm{Zn}, \quad$ (c) $]$ of metal alkyls with an ethylenediamine A. Reaction conditions: (a) hexane at $25^{\circ} \mathrm{C} 1 \mathrm{~h}$; (b) hexane at $25^{\circ} \mathrm{C}$ $24 \mathrm{~h}$ and at $69^{\circ} \mathrm{C} 10 \mathrm{~min}$; and (c) hexane at $69^{\circ} \mathrm{C} 2 \mathrm{~h}$.

To gauge whether a bimetallic mixture exhibits synergic activity, its separated monometallic components should be reacted with the substrate in control reactions. As expected, we found that $t \mathrm{Bu}_{2} \mathrm{Zn}$ is too weak a base to deprotonate $N, \quad N^{\prime}$ diisopropylethylenediamine, but instead forms the simple Lewis acid-Lewis base adduct $\left[t \mathrm{Bu}_{2} \mathrm{Zn} \cdot\left\{i \operatorname{PrN}(\mathrm{H}) \mathrm{CH}_{2} \mathrm{CH}_{2} \mathrm{~N}(\mathrm{H}) i \operatorname{Pr}\right\}\right] \mathbf{1}$ (Scheme 1 : see Supporting Information for full details). While we easily generated a crystalline product from a 1:1 reaction of the more powerful base $n \mathrm{BuLi}$ and the diamine, and characterised it spectroscopically as $\left[\left\{\mathrm{LiN}(i \mathrm{Pr}) \mathrm{CH}_{2} \mathrm{CH}_{2} \mathrm{~N}(\mathrm{H}) i \operatorname{Pr}\right\}\right]$, we deemed it unnecessary to determine its crystal structure as Gardiner and Raston had previously reported ${ }^{[4]}$ that the same reaction with the $t$-butyl homolog $t \mathrm{BuN}(\mathrm{H}) \mathrm{CH}_{2} \mathrm{CH}_{2} \mathrm{~N}(\mathrm{H}) t \mathrm{Bu}$ produced lithiation of one $\mathrm{N}-H$ unit in $\left[c i s-\left\{\mathrm{Li}\left[\mu-\mathrm{N}(t \mathrm{Bu}) \mathrm{CH}_{2} \mathrm{CH}_{2} \mathrm{~N}(\mathrm{H}) t \mathrm{Bu}\right]\right\}_{2}\right]$ 2, which is dimeric with a $5,4,5$-fused ring system having a $(\mathrm{LiN})_{2}$ core (Scheme 1). From the precedents of these homometallic zinc and lithium control reactions, in the absence of any co-operative interactions between the distinct metals one might anticipate that reaction of a $1: 1$ mixture of $t \mathrm{Bu}_{2} \mathrm{Zn}$ and $n \mathrm{BuLi}$ with $N, N^{\prime}$ diisopropylethylenediamine in the presence of TMEDA (one 
molar equivalent) would produce a co-complex of composition $\left[t \mathrm{Bu}_{2} \mathrm{Zn} \cdot\left\{i \operatorname{PrN}(\mathrm{Li} \cdot \mathrm{TMEDA}) \mathrm{CH}_{2} \mathrm{CH}_{2} \mathrm{~N}(\mathrm{H}) i \mathrm{Pr}\right\}\right]$ 3. Kinetically it does and we obtained the crystal structure of $\mathbf{3}$ (Figure 1). However, thermodynamically, this reaction mixture in hexane solution surprisingly affords the crystalline product $[(\mathrm{TMEDA}) \cdot \operatorname{Li}(i \operatorname{PrNCHCHN} i \operatorname{Pr}) \mathrm{Zn}(t \mathrm{Bu})]$ 4. As depicted in Scheme 1, formation of this lithium 1,3-diaza-2zincacyclopentene formally requires the loss of two protons and hydrogen gas to transform the neutral saturated ethylenediamine to a dianionic unsaturated variant. To check whether this transformation was the result of employing two or more equivalents of the metal reagent and/or adding TMEDA, a 3:1:0 and 3:1:3 mixture of $n \mathrm{BuLi}$, diamine, and TMEDA, in the absence of $t \mathrm{Bu}_{2} \mathrm{Zn}$, was evaluated but NMR spectroscopic studies confirmed only synthetically insignificant trace amounts of a diazaethene product with the major product being an ethylenediamine complex in which the $-\mathrm{NCH}_{2} \mathrm{CH}_{2} \mathrm{~N}$ - bridge is retained. ${ }^{[5]}$ On this evidence, the double $\left(\mathrm{sp}^{3}\right) \mathrm{C}-\mathrm{H}$ bond activation and concomitant $\mathrm{C}=\mathrm{C}$ formation involved in the making of the metallo cycloalkene $\mathbf{4}$ can be attributed at least in part to a special bimetallic synergic effect under the particular conditions studied, though other factors such as changing concentration may also be important as $\mathrm{C}=\mathrm{C}$ bond formation has been observed to occur in concentrated monometallic systems (see below).

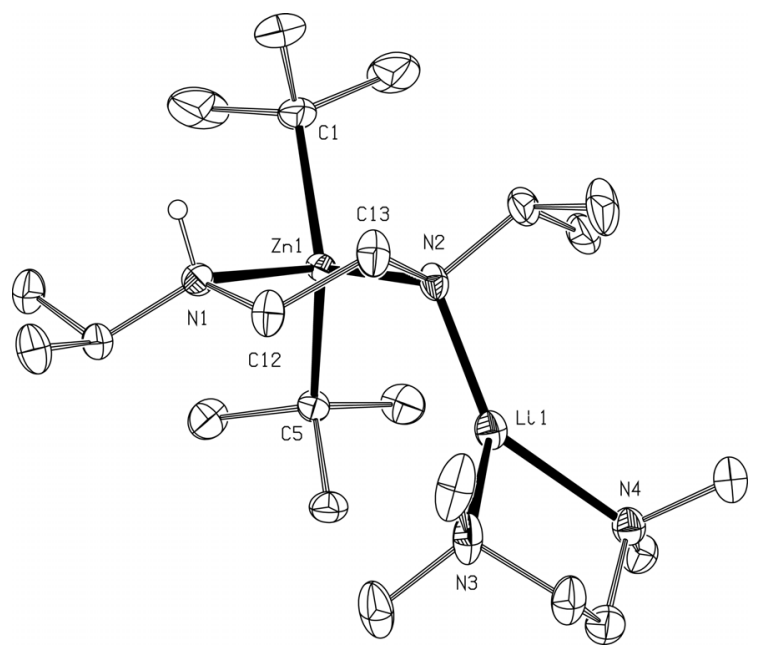

Figure 1. Molecular structure of $\mathbf{3}$ with hydrogen atoms (except $\mathrm{N}-H$ ) omitted for clarity. Selected bond lengths $[\AA]$ and angles $\left[{ }^{\circ}\right]$ : $\mathrm{Zn}(1)-\mathrm{C}(1)$ 2.073(2), $\mathrm{Zn}(1)-\mathrm{C}(5)$ 2.068(2), $\mathrm{Zn}(1)-\mathrm{N}(1)$ 2.326(1), $\mathrm{Zn}(1)-\mathrm{N}(2)$ 2.127(1), Li(1)-N(2) 1.993(3), Li(1)$\mathrm{N}(3) 2.143(3), \mathrm{Li}(1)-\mathrm{N}(4) 2.173(3), \mathrm{N}(1)-\mathrm{C}(12) 1.470(2), \mathrm{N}(2)-\mathrm{C}(13) 1.461(2)$, $\mathrm{C}(12)-\mathrm{C}(13)$ 1.517(2), C(5)-Zn(1)-C(1) 125.65(7), C(5)-Zn(1)-N(2) 111.49(6), $\mathrm{C}(5)-\mathrm{Zn}(1)-\mathrm{N}(1) \quad 108.98(5), \quad \mathrm{C}(5)-\mathrm{Zn}(1)-\mathrm{N}(2) \quad 111.49(56), \quad \mathrm{C}(1)-\mathrm{Zn}(1)-\mathrm{N}(1)$ 102.67(6), N(2)-Zn(1)-N(1) 83.10(5), N(2)-Li(1)-N(3) 127.12(15), N(2)-Li(1)$\mathrm{N}(4)$ 141.1(2), N(3)-Li(1)-N(4) 87.1(1).

Determined by X-ray crystallography, the molecular structures of $\mathbf{3}$ (Figure 1) and $\mathbf{4}$ can be classed as contact ion pair zincates comprising a TMEDA-chelated lithium cation and an alkyl(diamido) zinc anion. Within 3 distorted tetrahedral $\mathrm{Zn}(1)$ completes a highly puckered $\mathrm{C}_{2} \mathrm{~N}_{2} \mathrm{Zn}$ metallacyclic ring [see for instance torsion, $\left.\mathrm{Zn} 1-\mathrm{N} 2-\mathrm{C} 13-\mathrm{C} 12=-48.82(17)^{\circ}\right]$ with an $\mathrm{N}-$ $\mathrm{Zn}-\mathrm{N}$ bite angle of $83.10(5)^{\circ}$ with exo $t \mathrm{Bu}$ substituents on $\mathrm{Zn}$ and $i \mathrm{Pr} / \mathrm{H}$ and $i \mathrm{Pr} / \mathrm{Li}$ substituents on $\mathrm{N} 1$ and $\mathrm{N} 2$ respectively. The $i \mathrm{Pr}$ groups both occupy equatorial sites and lie anti to each other across the 5-atom ring which exhibits an ethylene $\mathrm{C}(12)-\mathrm{C}(13)$ bond length of 1.517(2) $\AA$ consistent with a single bond. Trigonal planar $\operatorname{Li}(1)$ has $\mathrm{N}_{3}$ coordination comprising one diamine atom and two $\mathrm{N}$ atoms of TMEDA with the formal anionic Li-N(2) bond [1.993(3) $\AA$ ] being shorter than the latter dative $\mathrm{Li}-\mathrm{N}$ bonds (mean length, $2.158 \AA$ ). Though the connectivity within 4 can be crystallographically determined, generic twinning of the samples adversely effected all modelling attempts and rules out discussion of its bonding dimensions. However, using an identical procedure to that for 4 , we synthesized and crystallographically characterized the isostructural methyl homolog [(TMEDA $) \cdot \operatorname{Li}(i \operatorname{PrNCHCHN} i \operatorname{Pr}) \mathrm{Zn}(\mathrm{Me})] \mathbf{5}$, the crystal data for which are more accurate allowing such a discussion. In the molecular structure of 5 (Figure 2) the anionic moiety shows $\mathrm{N}$, $\mathrm{N}^{\prime}$-chelation by the $\mathrm{N}-\mathrm{C}=\mathrm{C}-\mathrm{N}$ unit to zinc [bite angle, $83.98(9)^{\circ}$ ] to build a 5-atom metallacycle with exo $i \operatorname{Pr}$ and Me substituents on $\mathrm{N}$ and $\mathrm{Zn}$ atoms respectively. Distorted trigonal planar zinc deviates modestly from the $\mathrm{C}_{2} \mathrm{~N}_{2}$ plane, bonding symmetrically to the $\mathrm{N}$ atoms [lengths, 1.966(2) and 1.964(2) $\AA$; Zn 0.459(3) $\AA$ out of plane]. In a typical range for $\mathrm{sp}^{2}-\mathrm{sp}^{2} \mathrm{C}=\mathrm{C}$ bonds, the $\mathrm{C}(5)-\mathrm{C}(6)$ bond length is $1.349(3) \AA$. The $\mathrm{Li}^{+}$ion of the cationic moiety $\pi$ bonds $\left(\eta^{4}-\right)$ asymmetrically to the $\mathrm{N}-\mathrm{C}=\mathrm{C}-\mathrm{N}$ unit, closer to one end $[\mathrm{Li}(1)-\mathrm{N}(1), 2.165(4) \AA ; \mathrm{Li}(1)-\mathrm{C}(5), 2.235(4) \AA]$ than the other $[\mathrm{Li}(1)-\mathrm{N}(2), 2.301(4) \AA ; \quad \operatorname{Li}(1)-\mathrm{C}(6), 2.286(4) \AA]$. This asymmetry continues with $\mathrm{Li}$ anti to $\mathrm{Zn}$, with respect to the $\mathrm{C}_{2} \mathrm{~N}_{2}$ plane, and separated from it by 2.688(4) $\AA$. Though new for $\mathrm{Li}: \mathrm{Zn}$ combinations, the alkali metal face-capped 1,3-diaza-2metallocyclopentene motif of $\mathbf{4}$ and $\mathbf{5}$ is known for other combinations including for example $\mathrm{Na}: \mathrm{Zn},{ }^{[6]} \mathrm{K}: \mathrm{Zn},{ }^{[7]} \mathrm{K}: \mathrm{Mg},{ }^{[8]}$ $\mathrm{Li}: \mathrm{Ga},{ }^{[9]}$ or $\mathrm{K}: \mathrm{Ga}^{\left[{ }^{[10]}\right.}$ Most of these structural precedents originate from elemental alkali metal reduction of 1,4-diaza-1,3-butadienes or related unsaturated molecules which sets them synthetically apart from $\mathbf{4}$ and $\mathbf{5}$ as to the best of our knowledge these two $\mathrm{Li}: \mathrm{Zn}$ examples represent the first to be synthesized from a completely non-activated aliphatic diamine.

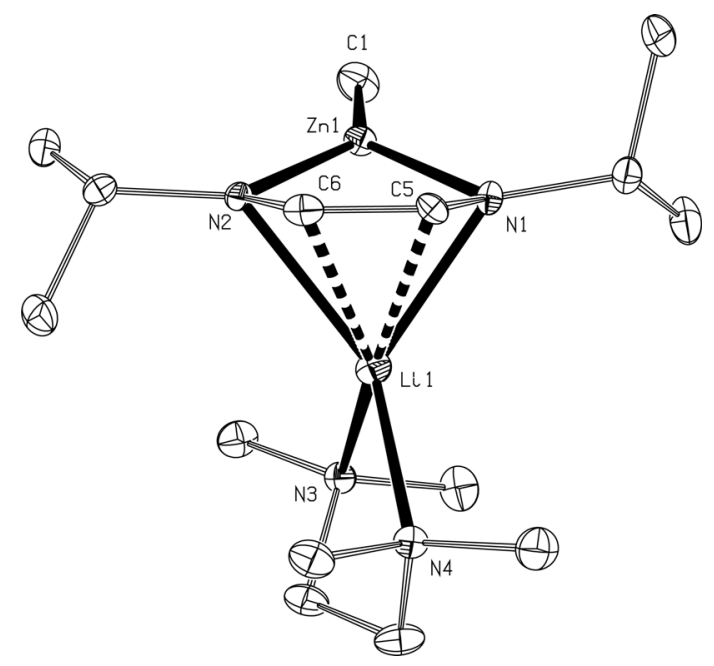

Figure 2. Molecular structure of $\mathbf{5}$ with hydrogen atoms omitted for clarity. Selected bond lengths $[\AA]$ and angles $\left[{ }^{\circ}\right]$ : $\mathrm{Zn}(1)-\mathrm{C}(1) 1.956(3), \mathrm{Zn}(1)-\mathrm{N}(1) 1.966(2), \mathrm{Zn}(1)$ $\mathrm{N}(2)$ 1.964(2), Zn(1)-Li(1) 2.688(4), Li(1)-N(1) 2.165(4), Li(1)-N(2) 2.301(4), $\mathrm{Li}(1)-\mathrm{N}(3)$ 2.145(4), $\mathrm{Li}(1)-\mathrm{N}(4) 2.106(4), \mathrm{Li}(1)-\mathrm{C}(5)$ 2.235(4), Li(1)-C(6) 2.286(4), $\mathrm{N}(1)-\mathrm{C}(5)$ 1.398(3), N(2)-C(6) 1.402(3), C(5)-C(6) 1.349(3), N(1)-C(5) 1.398(3), C(1)-Zn(1)-N(1) 136.6(1), C(1)-Zn(1)-N(2) 138.69(9), N(2)-Zn(1)-N(1) 83.98(9), $\mathrm{N}(2)-\mathrm{Li}(1)-\mathrm{N}(3)$ 112.5(2), N(4)-Li(1)-N(3) 86.51(16), N(4)-Li(1)-N(1) 126.8(2), $\mathrm{N}(3)-\mathrm{Li}(1)-\mathrm{N}(1)$ 124.6(2), N(4)-Li(1)-N(2) 139.9(2), N(1)-Li(1)-N(2) 72.1(1). 
The closest synthetic analogy to the reaction producing $\mathbf{4}$ and $\mathbf{5}$ is Veith's report ${ }^{[11 \mathrm{a}]}$ of the 1,3-diaza-2-silacyclopentene $\mathbf{6 a}$ as it involves dilithiation of $t \mathrm{BuN}(\mathrm{H}) \mathrm{CH}_{2} \mathrm{CH}_{2} \mathrm{~N}(\mathrm{H}) t \mathrm{Bu}$ (Scheme 2). Distinct from our method, the anticipated dianionic diamide was not isolated but trapped in situ with a dichlorosilane to generate the neutral, as opposed to our anionic, heterocyclopentene. Oddly, 6a formed only in highly concentrated solutions, ${ }^{[11 \mathrm{a}]}$ whereas dilute solutions, ${ }^{[11 \mathrm{~b}]}$ more akin to that employed in our study gave an alternative heterocyclopentane product $\mathbf{6 b}$. Veith conceded that the reason for the double hydrogen abstraction from the ethylene backbone in forming 6a was unclear. In theory $\mathbf{4}$ and $\mathbf{5}$ having potentially labile metal centers primed for participation in salt metathesis reactions could be regarded as intermediates in conversions of this type.
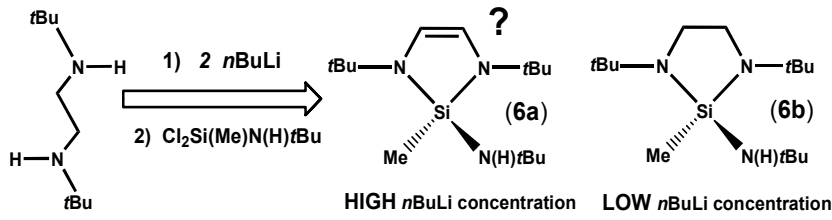

Scheme 2. Veith's reaction of $t \mathrm{BuN}(\mathrm{H}) \mathrm{CH}_{2} \mathrm{CH}_{2} \mathrm{~N}(\mathrm{H}) t \mathrm{Bu}$ with $n \mathrm{BuLi}$ and further trapping with a dichlorosilane.

A repeat reaction of $t \mathrm{Bu}_{2} \mathrm{Zn}, n \mathrm{BuLi}$, and the diamine in the additional presence of the bulky ketone $(t \mathrm{Bu})_{2} \mathrm{C}=\mathrm{O}$ (Scheme 3) may have provided an initial clue to the mechanism behind the formation of 4. An NMR analysis of the crude reaction revealed a complicated mixture of products, ${ }^{[5]}$ among which, significantly, 4 and the lithium alkoxide $\left[\left\{\mathrm{Bu}_{2} \mathrm{C}(\mathrm{H}) \mathrm{OLi}\right\}_{4}\right], 7$, were clearly identified. The existence of 7 , the result of a hydride addition to the electrophilic $C=\mathrm{O}$ of the ketone, hints at the possible participation of an intermediate hydride species in the $\mathrm{N}-\mathrm{CH}_{2}-$ $\mathrm{CH}_{2}-\mathrm{N}$ to $\mathrm{N}-\mathrm{CH}=\mathrm{CH}-\mathrm{N}$ transformation. While the source of the hydride cannot be ascertained with absolute certainty at this juncture, we could straightforwardly rule out that it was coming from either $n \mathrm{BuLi}$ or $t \mathrm{Bu}_{2} \mathrm{Zn},{ }^{[12]}$ suggesting that it originates from the ethylene backbone of the diamine. With monoamine dibenzylamine $\left[\left(\mathrm{PhCH}_{2}\right)_{2} \mathrm{NH}\right]$, it has been postulated ${ }^{[13]}$ that metalation of $\mathrm{N}-H$, followed by $\beta$-hydride elimination of " $\mathrm{M}^{+} \mathrm{H}^{-}$" and its subsequent metalation of the remaining $\mathrm{NCH}_{2}$ unit (accompanied by $\mathrm{H}_{2}$ evolution) accounts for the formation of the 2-aza-allyl anion $\left[\{\mathrm{PhC}(\mathrm{H})=\mathrm{N}-\mathrm{C}(\mathrm{H}) \mathrm{Ph}\}^{-}\right] . \quad$ Similar metalation $/ \beta$-hydride elimination/re-metalation sequences could be operating in the reaction yielding 4 . For completeness, isolated 7 was also crystallographically characterized. Its molecular structure (see the Supporting Information) is tetrameric with a heterocubane $\left[\left(\mu_{3}-\mathrm{OR}\right)_{4} \mathrm{Li}_{4}\right]$ core of a type well documented for lithium alkoxides. ${ }^{[14]}$ These precedents commonly possess additional donor ligands at the $\mathrm{Li}$ corners, so 7 belongs to a rarer type $^{[15]}$ wherein the large bulk of the $\mathrm{R}$ group promotes steric saturation of $\mathrm{Li}$ at the expense of electronic saturation.

Noting that the $\mathrm{N}-\mathrm{CH}_{2}-\mathrm{CH}_{2}-\mathrm{N}$ to $\mathrm{N}-\mathrm{CH}=\mathrm{CH}-\mathrm{N}$ transformation outlined here for certain will not involve redox processes like that reported by Brookhart ${ }^{[16]}$ for late transition metal catalysed intramolecular dehydrogenations, in future work we plan to carry out a comprehensive computational study to elucidate the mechanism of this transformation with emphasis on the precise role of the lithium-zinc co-operativity.

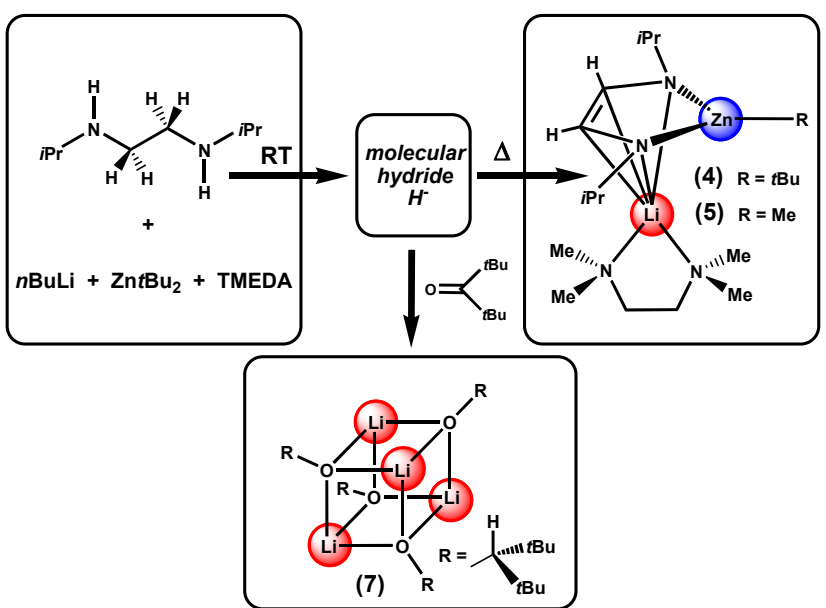

Scheme 3. Reaction of $\operatorname{iPrN}(\mathrm{H}) \mathrm{CH} 2 \mathrm{CH} 2 \mathrm{~N}(\mathrm{H}) \mathrm{Pr}$ with a nBuLi/R $2 \mathrm{Zn} / \mathrm{TMEDA}$ synergic mixture to form $\mathbf{4}$ or $\mathbf{5}$ via a putative intermediate hydride which can also be trapped with a ketone to generate a lithium alkoxide.

\section{Experimental Section}

General methods: All reactions and manipulations were carried out in an atmosphere of dry pure argon gas using standard Schlenk and glovebox techniques. $n$-Hexane was distilled from sodium-benzophenone. NMR spectra were recorded on a Bruker AVANCE 400 NMR spectrometer, operating at $400.13 \mathrm{MHz}$ for ${ }^{1} \mathrm{H}, 155.50$ $\mathrm{MHz}$ for ${ }^{7} \mathrm{Li}$ and $100.62 \mathrm{MHz}$ for ${ }^{13} \mathrm{C}$. Data for X-ray crystal structure determination were obtained with a Oxford Diffraction Gemini diffractometer using Mo-K $\alpha(\lambda=$ $0.71073 \AA$; compounds 5 and 7) and $\mathrm{Cu}-\mathrm{K} \alpha(\lambda=1.54180 \AA$; compounds 1 and $\mathbf{3})$ graphite monochromated radiations. Satisfactory elemental analyses of the compounds could not be obtained due to their high air- and moisture-sensitive nature.

Synthesis of 1: A Schlenk tube was charged with $4 \mathrm{mmol}(0.72 \mathrm{~g})$ of $\mathrm{Zn}^{t} \mathrm{Bu}_{2}$ which was dissolved in $20 \mathrm{~mL}$ of hexane and one equivalent of $i \operatorname{Pr}(\mathrm{H}) \mathrm{NCH}_{2} \mathrm{CH}_{2} \mathrm{CH}_{2} \mathrm{~N}(\mathrm{H}) i \operatorname{Pr}(4 \mathrm{mmol}, 0.72 \mathrm{~mL})$ was added via syringe. The resultant colourless solution was allowed to stir overnight at RT and heated at reflux temperature for $10 \mathrm{~min}$. To aid crystallisation the solution was concentrated under reduced pressure to a final volume of $2-3 \mathrm{~mL}$ and, after standing overnight at $-27^{\circ} \mathrm{C}$, colourless crystals of $\mathbf{1}$ (suitable for X-ray crystallographic analysis) were obtained $(0.20 \mathrm{~g}, 15 \%)$. The low crystalline yield obtained for $\mathbf{1}$ is just a reflection of its high solubility, being the overall reaction yield almost quantitative as determined by NMR spectroscopic analyses of both 1 and reaction filtrates. ${ }^{1} \mathrm{H}$ NMR $(400.13 \mathrm{MHz}$, $\mathrm{C}_{6} \mathrm{D}_{6}, 293 \mathrm{~K}$ ): $\delta=2.62(\mathrm{~m}, 2 \mathrm{H}, \mathrm{CH}, i \mathrm{Pr}), 2.02\left(\mathrm{~m}, 4 \mathrm{H}, \mathrm{CH}_{2}\right), 1.34\left(\mathrm{~s}, 18 \mathrm{H}, \mathrm{CH}_{3}\right.$, $t \mathrm{Bu}), 0.90\left(\mathrm{~d}, J=5.2 \mathrm{~Hz}, 12 \mathrm{H}, \mathrm{CH}_{3}, i \operatorname{Pr}\right), 0.85(\mathrm{~s}, \mathrm{br}, 2 \mathrm{H}, \mathrm{N} H) .{ }^{13} \mathrm{C}\left\{{ }^{1} \mathrm{H}\right\} \mathrm{NMR}$ $\left(100.62 \mathrm{MHz}, \mathrm{C}_{6} \mathrm{D}_{6}, 293 \mathrm{~K}\right): \delta=49.5(\mathrm{CH}, i \mathrm{Pr}), 47.2\left(\mathrm{CH}_{2}\right), 35.8\left(\mathrm{CH}_{3}, t \mathrm{Bu}\right), 23.1$ $\left(\mathrm{CH}_{3}, i \mathrm{Pr}\right), 19.9\left(\mathrm{C}\left(\mathrm{CH}_{3}\right), i \mathrm{Pr}\right)$.

Crystallisation of 3: $1.25 \mathrm{~mL}(2 \mathrm{mmol}) n$ BuLi was added dropwise to a solution of $0.36 \mathrm{~mL}(2 \mathrm{mmol}) \operatorname{DPEDA}\left(\mathrm{H}_{2}\right)$ in $10 \mathrm{~mL}$ hexane at $0{ }^{\circ} \mathrm{C}$. This temperature was maintained as $0.3 \mathrm{~mL}$ ( $2 \mathrm{mmol}$ ) TMEDA and a solution of $0.36 \mathrm{~g} \mathrm{(2} \mathrm{mmol)} t \mathrm{Bu}_{2} \mathrm{Zn}$ in $10 \mathrm{~mL}$ hexane were added giving a pale yellow solution with some white solid. This solution was stored immediately at $-27{ }^{\circ} \mathrm{C}$ giving a crop of colourless crystals suitable for X-ray crystallographic analysis corresponding to complex 3 . Attempts to characterise by NMR spectroscopy the kinetic product 3 resulted unsuccessful due to its high thermal instability.

Synthesis of 4: $1.25 \mathrm{~mL}(2 \mathrm{mmol}) n \mathrm{BuLi}$ was added dropwise to a solution of 0.36 $\mathrm{mL}(2 \mathrm{mmol}) \operatorname{DPEDA}\left(\mathrm{H}_{2}\right)$ in $10 \mathrm{~mL}$ hexane at $0{ }^{\circ} \mathrm{C}$. This temperature was maintained as $0.3 \mathrm{~mL}$ ( $2 \mathrm{mmol}$ ) TMEDA and a solution of $0.36 \mathrm{~g} \mathrm{(2} \mathrm{mmol)} t \mathrm{Bu}_{2} \mathrm{Zn}$ in $10 \mathrm{~mL}$ hexane were added giving a pale yellow solution with some white solid. 
This solution was refluxed for 2 hours producing a bright orange solution. Storing the solution at $-70{ }^{\circ} \mathrm{C}$ gave a crop of yellow crystals of $\mathbf{4}$ which were isolated in a $38.9 \%(0.30 \mathrm{~g})$ crystalline yield. ${ }^{1} \mathrm{H}$ NMR $\left(400.13 \mathrm{MHz}, \mathrm{C}_{6} \mathrm{D}_{6}, 300 \mathrm{~K}\right): \delta(\mathrm{ppm})=$ 5.83 (s, $2 \mathrm{H}, \mathrm{CH}, \mathrm{CH}=\mathrm{CH}$ ), 3.48 (m, $2 \mathrm{H}, \mathrm{CH}, i \mathrm{Pr}), 1.81$ (s, $12 \mathrm{H}, \mathrm{CH}_{3}$, TMEDA), 1.60 (s, $\left.9 \mathrm{H}, \mathrm{CH}_{3}, t \mathrm{Bu}\right), 1.58$ (s, $4 \mathrm{H}, \mathrm{CH}_{2}$, TMEDA), 1.40 (d, $J=6.3 \mathrm{~Hz}, 6 \mathrm{H}, \mathrm{CH}_{3}$, $i \operatorname{Pr}), 1.32\left(\mathrm{~d}, J=6.3 \mathrm{~Hz}, 6 \mathrm{H}, \mathrm{CH}_{3}, i \mathrm{Pr}\right) .{ }^{13} \mathrm{C}\left\{{ }^{1} \mathrm{H}\right\} \mathrm{NMR}\left(100.62 \mathrm{MHz}, \mathrm{C}_{6} \mathrm{D}_{6}, 300 \mathrm{~K}\right)$ : $\delta(\mathrm{ppm})=116.3(\mathrm{CH}, \mathrm{CH}=\mathrm{CH}), 56.0\left(\mathrm{CH}_{2}, \mathrm{TMEDA}\right), 52.7(\mathrm{CH}, i \mathrm{Pr}), 45.6\left(\mathrm{CH}_{3}\right.$,

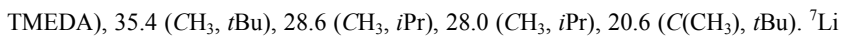
$\left(155.50 \mathrm{MHz}, \mathrm{C}_{6} \mathrm{D}_{6}, 300 \mathrm{~K}\right): \delta(\mathrm{ppm})=-2.40$.

\section{Acknowledgements}

We gratefully acknowledge the generous support of the UK EPSRC (grant award no. EP/F063733/1) and the Royal Society/Wolfson Foundation (research merit award to R.E.M). We also thank our colleague Dr Eva Hevia for many enlightening discussions. This research was also sponsored by a Marie Curie Intra European Fellowship within the $7^{\text {th }}$ European Community Framework Programme (for P.G.A.).

\section{Keywords: amines $\cdot$ diamines $\cdot$ hydride $\cdot$ lithium $\cdot$} metallacycle $\cdot$ synergy $\cdot$ zinc

[1] For recent reviews on alkali metal zincates and their applications in metalation applications, see : a) R. E. Mulvey, Organometallics 2006, 25, 1060; b) R. E. Mulvey, F. Mongin, M. Uchiyama, Y. Kondo, Angew. Chem. 2007, 119, 3876; Angew. Chem. Int. Ed. 2007, 46, 3802; c) R.E. Mulvey, Acc. Chem. Res. 2009, 42, 743

[2] a) J.-M. L'Helgoual'ch, G. Bentabed-Ababsa, F. Chevallier, M. Yonehara, M. Uchiyama, A. Derdour, F. Mongin, Chem. Commun. 2008, 5375; b) G. Dayaker, A. Sreeshailam, F. Chevallier, T. Roisnel, P. R. Krishna, F. Mongin, Chem. Commun. 2010, 46, 2862; c) K. Snegaroff, J.-M. L'Helgoual'ch, G. Bentabed-Ababsa, T. T. Nguyen, F. Chevallier, M. Yonehara, M. Uchiyama, A. Derdour, F. Mongin, Chem. Eur. J. 2009, 15, 10280; d) A. Seggio, G. Priem, F. Chevallier, F. Mongin, Synthesis 2009, 3617; e) A. Seggio, M.-I. Lannou, F. Chevallier, D. Nobuto, M. Uchiyama, S. Golhen, T. Roisnel, F. Mongin, Chem. Eur. J. 2007, 13, 9982; f) A. Seggio, F. Chevallier, M. Vaultier, F. Mongin, J. Org. Chem. 2007, 72, 6602; g) J.-M. L'Helgoual'ch, A. Seggio, F. Chevallier, M. Yonehara, E. Jeanneau, M. Uchiyama, F. Mongin, J. Org. Chem. 2008, 73, 177; h) M. Uchiyama, Y. Matsumoto, S. Usui, Y. Hashimoto, K. Morokuma, Angew. Chem. 2007, 119, 944; Angew. Chem., Int. Ed. 2007, 46, 926; i) M. Uchiyama, Y. Kobayashi, T. Furuyama, S. Nakamura, Y. Kajihara, T. Miyoshi, T. Sakamoto, Y. Kondo, K. Morokuma, J. Am. Chem. Soc. 2008, 130, 472; j) Y. Kondo, J. V. Morey, J. C. Morgan, H. Naka, D. Nobuto, P. R. Raithby, M. Uchiyama, A. E. H. Wheatley, J. Am. Chem. Soc. 2007, 129, 12734; k) F. Garcia, M. McPartlin, J. V. Morey, D. Nobuto, Y. Kondo, H. Naka, M. Uchiyama, A. E. H. Wheatley, Eur. J. Org. Chem. 2008, 644; 1) W. Clegg, D. V. Graham, E. Herd, E. Hevia, A. R. Kennedy, M. D. McCall, L. Russo, Inorg. Chem. 2009, 48, 5320; m) E. Hevia, A. R. Kennedy, J. Klett, M. D. McCall, Chem. Commun. 2009, 3240; n) D. R. Armstrong, E. Herd, D. V. Graham, E. Hevia, A. R. Kennedy, W. Clegg, L. Russo, Dalton Trans. 2008, 1323; o) D. R. Armstrong, A. M. Drummond, L. Balloch, D. V. Graham, E. Hevia, A. R. Kennedy, Organometallics 2008, 27, 5860; p) W. Clegg, S. H. Dale, E. Hevia, L. M. Hogg, G. W. Honeyman, R. E. Mulvey, C. T. O'Hara, Angew. Chem. 2006, 118, 6698; Angew. Chem., Int. Ed. 2006, 45, 6548; q) D. R. Armstrong, J. Garcia-Alvarez, D. V. Graham, G. W. Honeyman, E. Hevia, A. R. Kennedy, R. E. Mulvey, Chem. Eur. J. 2009, 15, 3800; r) D. R. Armstrong, W. Clegg, S. H. Dale, E. Hevia, L. M. Hogg, G.
W. Honeyman, R. E. Mulvey, Angew. Chem. 2006, 118, 3859; Angew. Chem., Int. Ed. 2006, 45, 3775; s) D. R. Armstrong, L. Balloch, W. Clegg, S. H. Dale, P. Garcia-Alvarez, E. Hevia, L. M. Hogg, A. R. Kennedy, R. E. Mulvey, C. T. O'Hara, Angew. Chem. 2009, 121, 8831; Angew. Chem., Int. Ed. 2009, 48, 8675; t) P. C. Andrikopoulos, D. R. Armstrong, H. R. L. Barley, W. Clegg, S. H. Dale, E. Hevia, G. W. Honeyman, A. R. Kennedy, R. E. Mulvey, J. Am. Chem. Soc. 2005, 127, 6184.

[3] a) S. Wunderlich, P. Knochel, Chem. Commun. 2008, 6387; b) M. Mosrin, G. Monzon, T. Bresser, P. Knochel, Chem. Commun. 2009, 5615; c) S. H. Wunderlich, C. J. Rohbogner, A. Unsinn, P. Knochel, Org. Process Res. Dev. 2010, 14, 339; d) S. Wunderlich, P. Knochel, Org. Lett. 2008, 10 , 4705; e) M. Mosrin, P. Knochel, Chem. Eur. J. 2009, 15, 1468; f) M Mosrin, P. Knochel, Org. Lett. 2009, 11, 1837; g) Z. Dong, G. C. Clososki, S. H. Wunderlich, A. Unsinn, J. Li, P. Knochel, Chem. Eur. J. 2009, 15, 457; h) E. Hevia, J. Z. Chua, P. Garcia-Alvarez, A. R. Kennedy, M. D. McCall, Proc. Natl. Acad. Sci. U. S. A. 2010, 107, 5294.

[4] M. G. Gardiner, C. L. Raston, Inorg.Chem. 1996, 35, 4047.

[5] See Supporting Information for full experimental and crystallographic details.

[6] X.-J. Yang, J. Yu, Y. Liu, Y. Xie, H. F. Schaefer, Y. Liang, B. Wu, Chem.Commun. 2007, 2363.

[7] E. Rijnberg, J. Boersma, J. T. B. H. Jastrzebski, M. T. Lakin, A. L. Spek, G. Van Koten, Chem.Commun. 1995, 1839.

[8] Y. Liu, S. Li, X.-J. Yang, P. Yang, B. Wu, J. Am. Chem. Soc. 2009, 131, 4210.

[9] E. S. Schmidt, N. W. Mitzel, H. Schmidbaur, Z. Naturforsch., B: Chem. Sci. 2001, 56, 937.

[10] S. Aldridge, R. J. Baker, N. D. Coombs, C. Jones, R. P. Rose, A. Rossin, D. J. Willock, Dalton Trams. 2006, 3313.

[11] a) M. Veith, B. Schillo, V. Huch, Angew. Chem. 1999, 111, 131; Angew. Chem. Int. Ed. 1999, 38, 182; b) M. Veith, A. Rammo, Z. Anorg. Allg. Chem. 1997, 623, 861 .

[12] Note that in the synthesis of $\mathbf{4}$ the order of addition of the metal reagents to the diamine is not crucial, as $t \mathrm{Bu}_{2} \mathrm{Zn}$ or $n \mathrm{BuLi}$ can be introduced first. In the latter case all the $n \mathrm{BuLi}$ is consumed in forming a lithium amide before the zinc reagent is applied. This rules out the possibility that in the ketone reaction the hydride comes from the lithium reagent, a point confirmed by a control reaction between $n \mathrm{BuLi}$ and the ketone which did not produce a reduction product. The other possibility that $\mathrm{H}^{-}$was coming from $t \mathrm{Bu}$ groups on zinc was also ruled out as the reaction proved repeatable with $\mathrm{Me}_{2} \mathrm{Zn}$ forming 5 .

[13] a) P. C. Andrews, D. R. Armstrong, D. R. Baker, R. E. Mulvey, W. Clegg, L. Horsburgh, P. A. O'Neil, D. Reed, Organometallics 1995, 14, 427; b) P. C. Andrews, P. J. Duggan, G. D. Fallon, T. D. McCarthy, A. C. Peatt, $J$ Chem. Soc. Dalton Trans. 2000, 2505; c) P. C. Andrews, P. J. Duggan, M. Maguire, P. J. Nichols, Chem.Commun. 2001, 53.

[14] See for example: a) T. J. Boyle, D. M. Pedrotty, T. M. Alam, S. C. Vick, M. A. Rodriguez, Inorg. Chem. 2000, 39, 5133; b) T. J. Boyle, T. M. Alam, K. P. Peters, M. A. Rodriguez, Inorg. Chem. 2001, 40, 6281.

[15] See for example: a) U. Piarulli, D. N. Williams, C. Floriani, G. Gervasio, D. Viterbo, Chem. Commun. 1994, 1409; b) A. Reisinger, N. Trapp, I. Krossing, Organometallics 2007, 26, 2096.

[16] a) M. M. Diaz-Requejo, D. Disalvo, M. Brookhart, J. Am. Chem. Soc. 2003, 125, 2038; b) A. D. Bolig, M Brookhart, J. Am. Chem. Soc. 2007, 129 , 14544.

Received: ((will be filled in by the editorial staff))

Revised: ((will be filled in by the editorial staff)) Published online: ((will be filled in by the editorial staff)) 
Entry for the Table of Contents (Please choose one layout only)

\section{Layout 1:}

Metal-Mediated Synthesis

Ross Campbell, Pablo García-

Álvarez, * Alan R. Kennedy, and

Robert E. Mulvey*

Page - Page

Synergic Transformation of an Ethylenediamine to a Lithium 1, 3-Diaza-2-zincacyclopentene via an Alkyllithium/Bis(alkyl)zinc Mixture
Deadly Duo: Four bonds in total, two $\mathrm{N}-\mathrm{H}$ and two C-H bonds have been cleaved from a neutral secondary diamine through the cooperative effects of a lithium alkyl-zinc bisalkyl coalition aided by TMEDA to generate a dianionic diazaethene. 


\title{
Synergic Transformation of an Ethylenediamine to a Lithium 1, 3-Diaza-2- zincacyclopentene via an Alkyllithium/Bis(alkyl)zinc Mixture
}

\author{
Ross Campbell, Pablo García-Álvarez,* Alan R. Kennedy, and Robert E. Mulvey*ª]
}

\begin{abstract}
Alkali metal zincates are among an increasing number of mixedmetal organoreagents that are attracting widespread attention because of their ability to exhibit synergic reactivity. Such special behaviour can be defined as reactions arising from the cooperative effects of the two distinct metals, the hard alkali metal and soft zinc, within the multicomponent zincate that cannot be reproduced by either single alkali metal or zinc component on its own. This synergism has been particularly prominent in metalation (metal-hydrogen exchange) applications. ${ }^{[1]}$ Alkylzinc $\left(\mathrm{R}_{2} \mathrm{Zn}\right)$ or amidozinc $\left[\mathrm{RZn}\left(\mathrm{NR}_{2}^{\prime}\right) / \mathrm{Zn}\left(\mathrm{NR}_{2}\right)_{2}\right]$ reagents are generally notoriously poor kinetic bases incapable of directly metalating (zincating) aromatic substrates to any synthetically useful extent, but combined with an alkali metal compound ${ }^{[2]}$ or related component ${ }^{[3]}$ they can transform into highly reactive "zincators". Kondo and Uchiyama's "LiZn(TMP) $t \mathrm{Bu}_{2}$ " (TMP = 2,2,6,6-tetramethylpiperidide), Mongin's "LiZn(TMP) $)_{3}$, , ${ }^{[2 a-j]}$ and our own [(TMEDA) Na(TMP) $(t \mathrm{Bu}) \mathrm{Zn}(t \mathrm{Bu})]^{[2 \mathrm{p}-\mathrm{t}]} \quad(\mathrm{TMEDA}=$ $N, N, N$, $N$ '-tetramethylethylenediamine) belong in this category and although fundamental differences exist between these powerful amide-based zincators, their $\mathrm{Zn}-\mathrm{H}$ exchange reactions can be grouped together as alkali-metal-mediated zincations "AMMZn's". [1] Exemplified by TMP, the amide components involved in $\mathrm{AMM} Z n$ chemistry are invariably monoanionic ligands derived from secondary amines containing one acidic $\mathrm{N}-H$ bond. Secondary diamines containing two acidic $\mathrm{N}-H$ bonds and therefore having potentially at least two metalation sites would offer an interesting contrast but until this work they have not been investigated in this context. Reported herein, our first venture in introducing diamines to this chemistry by reacting a mixture of $n \mathrm{BuLi}$ and $t \mathrm{Bu}_{2} \mathrm{Zn}$ (or $\mathrm{Me}_{2} \mathrm{Zn}$ ) with $N, N^{\prime}-$ diisopropylethylenediamine $i \operatorname{PrN}(\mathrm{H}) \mathrm{CH}_{2} \mathrm{CH}_{2} \mathrm{~N}(\mathrm{H}) i \mathrm{Pr}$ has uncovered a surprising new synergic chemistry which leads ultimately to the transformation of the saturated ethylenediamine to a dianionic unsaturated diazaethene.
\end{abstract}

[a] R. Campbell, Dr P. García-Álvarez, Dr A. R. Kennedy, Prof R. E. Mulvey WestCHEM, Department of Pure and Applied Chemistry

University of Strathclyde

Glasgow G1 1XL (UK)

Fax: (+)44 141-548 4822

E-mail: r.e.mulvey@strath.ac.uk

Supporting information for this article is available on the WWW under http://www.chemeurj.org/ or from the author.

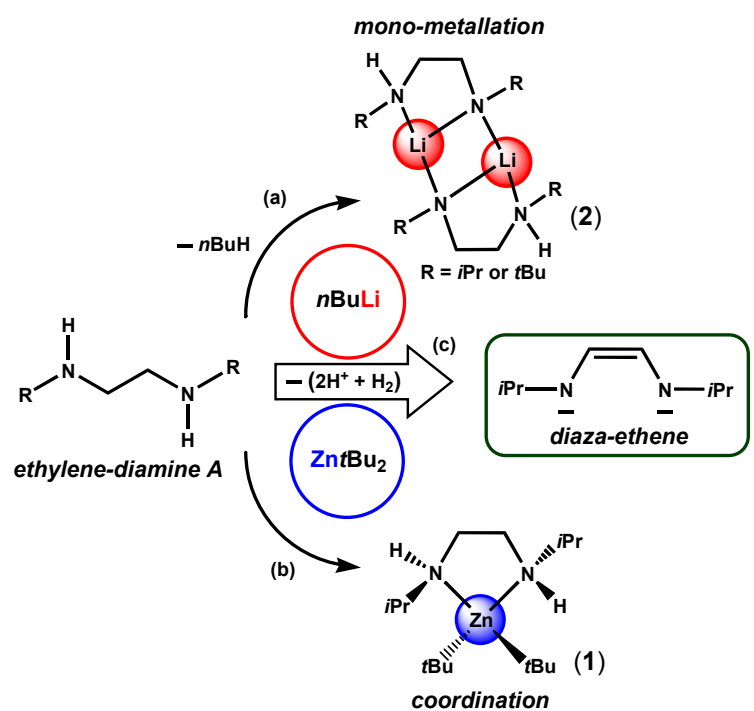

Scheme 1. Comparison of non-cooperative reactions $\left[n \mathrm{BuLi}\right.$, (a) or $t \mathrm{Bu}_{2} \mathrm{Zn}$, (b)] and cooperative reactions $\left[n \mathrm{BuLi}\right.$ and $t \mathrm{Bu}_{2} \mathrm{Zn}, \quad$ (c) $]$ of metal alkyls with an ethylenediamine A. Reaction conditions: (a) hexane at $25^{\circ} \mathrm{C} 1 \mathrm{~h}$; (b) hexane at $25^{\circ} \mathrm{C}$ $24 \mathrm{~h}$ and at $69^{\circ} \mathrm{C} 10 \mathrm{~min}$; and (c) hexane at $69^{\circ} \mathrm{C} 2 \mathrm{~h}$.

To gauge whether a bimetallic mixture exhibits synergic activity, its separated monometallic components should be reacted with the substrate in control reactions. As expected, we found that $t \mathrm{Bu}_{2} \mathrm{Zn}$ is too weak a base to deprotonate $N, \quad N^{\prime}$ diisopropylethylenediamine, but instead forms the simple Lewis acid-Lewis base adduct $\left[t \mathrm{Bu}_{2} \mathrm{Zn} \cdot\left\{i \operatorname{PrN}(\mathrm{H}) \mathrm{CH}_{2} \mathrm{CH}_{2} \mathrm{~N}(\mathrm{H}) i \operatorname{Pr}\right\}\right] \mathbf{1}$ (Scheme 1 : see Supporting Information for full details). While we easily generated a crystalline product from a 1:1 reaction of the more powerful base $n \mathrm{BuLi}$ and the diamine, and characterised it spectroscopically as $\left[\left\{\mathrm{LiN}(i \mathrm{Pr}) \mathrm{CH}_{2} \mathrm{CH}_{2} \mathrm{~N}(\mathrm{H}) i \operatorname{Pr}\right\}\right]$, we deemed it unnecessary to determine its crystal structure as Gardiner and Raston had previously reported ${ }^{[4]}$ that the same reaction with the $t$-butyl homolog $t \mathrm{BuN}(\mathrm{H}) \mathrm{CH}_{2} \mathrm{CH}_{2} \mathrm{~N}(\mathrm{H}) t \mathrm{Bu}$ produced lithiation of one $\mathrm{N}-H$ unit in $\left[c i s-\left\{\mathrm{Li}\left[\mu-\mathrm{N}(t \mathrm{Bu}) \mathrm{CH}_{2} \mathrm{CH}_{2} \mathrm{~N}(\mathrm{H}) t \mathrm{Bu}\right]\right\}_{2}\right]$ 2, which is dimeric with a $5,4,5$-fused ring system having a $(\mathrm{LiN})_{2}$ core (Scheme 1). From the precedents of these homometallic zinc and lithium control reactions, in the absence of any co-operative interactions between the distinct metals one might anticipate that reaction of a $1: 1$ mixture of $t \mathrm{Bu}_{2} \mathrm{Zn}$ and $n \mathrm{BuLi}$ with $N, N^{\prime}$ diisopropylethylenediamine in the presence of TMEDA (one 
molar equivalent) would produce a co-complex of composition $\left[t \mathrm{Bu}_{2} \mathrm{Zn} \cdot\left\{i \operatorname{PrN}(\mathrm{Li} \cdot \mathrm{TMEDA}) \mathrm{CH}_{2} \mathrm{CH}_{2} \mathrm{~N}(\mathrm{H}) i \mathrm{Pr}\right\}\right]$ 3. Kinetically it does and we obtained the crystal structure of $\mathbf{3}$ (Figure 1). However, thermodynamically, this reaction mixture in hexane solution surprisingly affords the crystalline product $[(\mathrm{TMEDA}) \cdot \operatorname{Li}(i \operatorname{PrNCHCHN} i \operatorname{Pr}) \mathrm{Zn}(t \mathrm{Bu})]$ 4. As depicted in Scheme 1, formation of this lithium 1,3-diaza-2zincacyclopentene formally requires the loss of two protons and hydrogen gas to transform the neutral saturated ethylenediamine to a dianionic unsaturated variant. To check whether this transformation was the result of employing two or more equivalents of the metal reagent and/or adding TMEDA, a 3:1:0 and 3:1:3 mixture of $n \mathrm{BuLi}$, diamine, and TMEDA, in the absence of $t \mathrm{Bu}_{2} \mathrm{Zn}$, was evaluated but NMR spectroscopic studies confirmed only synthetically insignificant trace amounts of a diazaethene product with the major product being an ethylenediamine complex in which the $-\mathrm{NCH}_{2} \mathrm{CH}_{2} \mathrm{~N}$ - bridge is retained. ${ }^{[5]}$ On this evidence, the double $\left(\mathrm{sp}^{3}\right) \mathrm{C}-\mathrm{H}$ bond activation and concomitant $\mathrm{C}=\mathrm{C}$ formation involved in the making of the metallo cycloalkene $\mathbf{4}$ can be attributed at least in part to a special bimetallic synergic effect under the particular conditions studied, though other factors such as changing concentration may also be important as $\mathrm{C}=\mathrm{C}$ bond formation has been observed to occur in concentrated monometallic systems (see below).

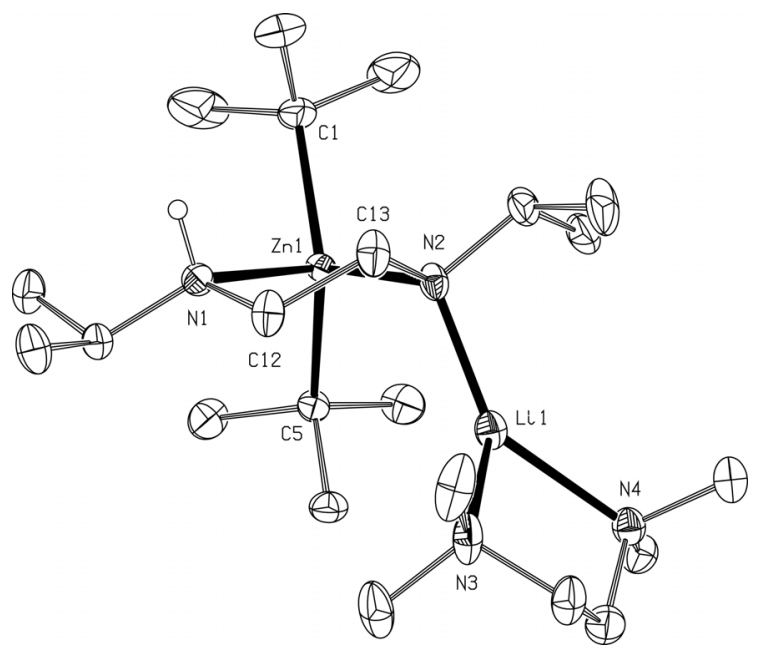

Figure 1. Molecular structure of $\mathbf{3}$ with hydrogen atoms (except $\mathrm{N}-H$ ) omitted for clarity. Selected bond lengths $[\AA]$ and angles $\left[{ }^{\circ}\right]$ : $\mathrm{Zn}(1)-\mathrm{C}(1)$ 2.073(2), $\mathrm{Zn}(1)-\mathrm{C}(5)$ 2.068(2), $\mathrm{Zn}(1)-\mathrm{N}(1)$ 2.326(1), $\mathrm{Zn}(1)-\mathrm{N}(2)$ 2.127(1), Li(1)-N(2) 1.993(3), Li(1)$\mathrm{N}(3) 2.143(3), \mathrm{Li}(1)-\mathrm{N}(4) 2.173(3), \mathrm{N}(1)-\mathrm{C}(12) 1.470(2), \mathrm{N}(2)-\mathrm{C}(13) 1.461(2)$, $\mathrm{C}(12)-\mathrm{C}(13)$ 1.517(2), C(5)-Zn(1)-C(1) 125.65(7), C(5)-Zn(1)-N(2) 111.49(6), $\mathrm{C}(5)-\mathrm{Zn}(1)-\mathrm{N}(1) \quad 108.98(5), \quad \mathrm{C}(5)-\mathrm{Zn}(1)-\mathrm{N}(2) \quad 111.49(56), \quad \mathrm{C}(1)-\mathrm{Zn}(1)-\mathrm{N}(1)$ 102.67(6), N(2)-Zn(1)-N(1) 83.10(5), N(2)-Li(1)-N(3) 127.12(15), N(2)-Li(1)$\mathrm{N}(4)$ 141.1(2), N(3)-Li(1)-N(4) 87.1(1).

Determined by X-ray crystallography, the molecular structures of $\mathbf{3}$ (Figure 1) and $\mathbf{4}$ can be classed as contact ion pair zincates comprising a TMEDA-chelated lithium cation and an alkyl(diamido) zinc anion. Within 3 distorted tetrahedral $\mathrm{Zn}(1)$ completes a highly puckered $\mathrm{C}_{2} \mathrm{~N}_{2} \mathrm{Zn}$ metallacyclic ring [see for instance torsion, $\left.\mathrm{Zn} 1-\mathrm{N} 2-\mathrm{C} 13-\mathrm{C} 12=-48.82(17)^{\circ}\right]$ with an $\mathrm{N}-$ $\mathrm{Zn}-\mathrm{N}$ bite angle of $83.10(5)^{\circ}$ with exo $t \mathrm{Bu}$ substituents on $\mathrm{Zn}$ and $i \mathrm{Pr} / \mathrm{H}$ and $i \mathrm{Pr} / \mathrm{Li}$ substituents on $\mathrm{N} 1$ and $\mathrm{N} 2$ respectively. The $i \mathrm{Pr}$ groups both occupy equatorial sites and lie anti to each other across the 5-atom ring which exhibits an ethylene $\mathrm{C}(12)-\mathrm{C}(13)$ bond length of 1.517(2) $\AA$ consistent with a single bond. Trigonal planar $\operatorname{Li}(1)$ has $\mathrm{N}_{3}$ coordination comprising one diamine atom and two $\mathrm{N}$ atoms of TMEDA with the formal anionic Li-N(2) bond [1.993(3) $\AA$ ] being shorter than the latter dative $\mathrm{Li}-\mathrm{N}$ bonds (mean length, $2.158 \AA$ ). Though the connectivity within 4 can be crystallographically determined, generic twinning of the samples adversely effected all modelling attempts and rules out discussion of its bonding dimensions. However, using an identical procedure to that for 4 , we synthesized and crystallographically characterized the isostructural methyl homolog [(TMEDA $) \cdot \operatorname{Li}(i \operatorname{PrNCHCHN} i \operatorname{Pr}) \mathrm{Zn}(\mathrm{Me})] \mathbf{5}$, the crystal data for which are more accurate allowing such a discussion. In the molecular structure of 5 (Figure 2) the anionic moiety shows $\mathrm{N}$, $\mathrm{N}^{\prime}$-chelation by the $\mathrm{N}-\mathrm{C}=\mathrm{C}-\mathrm{N}$ unit to zinc [bite angle, $83.98(9)^{\circ}$ ] to build a 5-atom metallacycle with exo $i \operatorname{Pr}$ and Me substituents on $\mathrm{N}$ and $\mathrm{Zn}$ atoms respectively. Distorted trigonal planar zinc deviates modestly from the $\mathrm{C}_{2} \mathrm{~N}_{2}$ plane, bonding symmetrically to the $\mathrm{N}$ atoms [lengths, 1.966(2) and 1.964(2) $\AA$; Zn 0.459(3) $\AA$ out of plane]. In a typical range for $\mathrm{sp}^{2}-\mathrm{sp}^{2} \mathrm{C}=\mathrm{C}$ bonds, the $\mathrm{C}(5)-\mathrm{C}(6)$ bond length is $1.349(3) \AA$. The $\mathrm{Li}^{+}$ion of the cationic moiety $\pi$ bonds $\left(\eta^{4}-\right)$ asymmetrically to the $\mathrm{N}-\mathrm{C}=\mathrm{C}-\mathrm{N}$ unit, closer to one end $[\mathrm{Li}(1)-\mathrm{N}(1), 2.165(4) \AA ; \mathrm{Li}(1)-\mathrm{C}(5), 2.235(4) \AA]$ than the other $[\mathrm{Li}(1)-\mathrm{N}(2), 2.301(4) \AA ; \quad \operatorname{Li}(1)-\mathrm{C}(6), 2.286(4) \AA]$. This asymmetry continues with $\mathrm{Li}$ anti to $\mathrm{Zn}$, with respect to the $\mathrm{C}_{2} \mathrm{~N}_{2}$ plane, and separated from it by 2.688(4) $\AA$. Though new for $\mathrm{Li}: \mathrm{Zn}$ combinations, the alkali metal face-capped 1,3-diaza-2metallocyclopentene motif of $\mathbf{4}$ and $\mathbf{5}$ is known for other combinations including for example $\mathrm{Na}: \mathrm{Zn},{ }^{[6]} \mathrm{K}: \mathrm{Zn},{ }^{[7]} \mathrm{K}: \mathrm{Mg},{ }^{[8]}$ $\mathrm{Li}: \mathrm{Ga},{ }^{[9]}$ or $\mathrm{K}: \mathrm{Ga}^{\left[{ }^{[10]}\right.}$ Most of these structural precedents originate from elemental alkali metal reduction of 1,4-diaza-1,3-butadienes or related unsaturated molecules which sets them synthetically apart from $\mathbf{4}$ and $\mathbf{5}$ as to the best of our knowledge these two $\mathrm{Li}: \mathrm{Zn}$ examples represent the first to be synthesized from a completely non-activated aliphatic diamine.

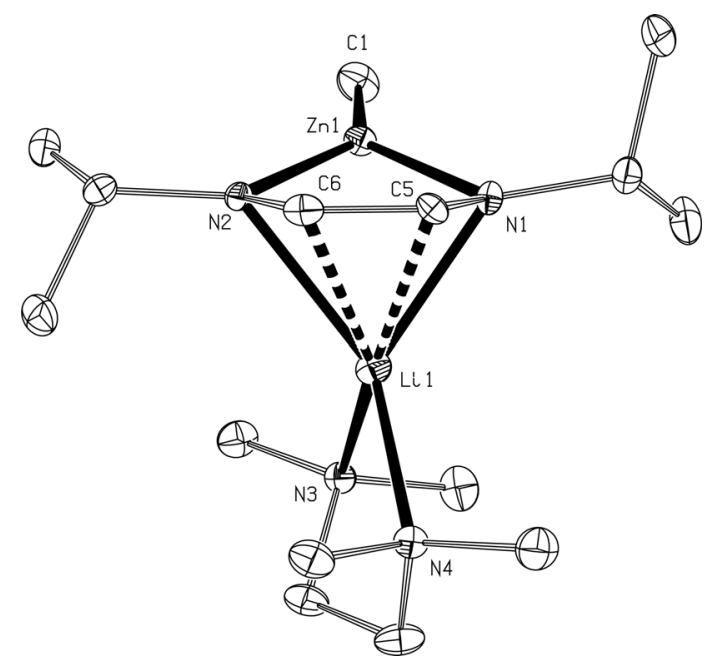

Figure 2. Molecular structure of $\mathbf{5}$ with hydrogen atoms omitted for clarity. Selected bond lengths $[\AA]$ and angles $\left[{ }^{\circ}\right]$ : $\mathrm{Zn}(1)-\mathrm{C}(1) 1.956(3), \mathrm{Zn}(1)-\mathrm{N}(1) 1.966(2), \mathrm{Zn}(1)$ $\mathrm{N}(2)$ 1.964(2), Zn(1)-Li(1) 2.688(4), Li(1)-N(1) 2.165(4), Li(1)-N(2) 2.301(4), $\mathrm{Li}(1)-\mathrm{N}(3)$ 2.145(4), $\mathrm{Li}(1)-\mathrm{N}(4) 2.106(4), \mathrm{Li}(1)-\mathrm{C}(5)$ 2.235(4), Li(1)-C(6) 2.286(4), $\mathrm{N}(1)-\mathrm{C}(5)$ 1.398(3), N(2)-C(6) 1.402(3), C(5)-C(6) 1.349(3), N(1)-C(5) 1.398(3), C(1)-Zn(1)-N(1) 136.6(1), C(1)-Zn(1)-N(2) 138.69(9), N(2)-Zn(1)-N(1) 83.98(9), $\mathrm{N}(2)-\mathrm{Li}(1)-\mathrm{N}(3)$ 112.5(2), N(4)-Li(1)-N(3) 86.51(16), N(4)-Li(1)-N(1) 126.8(2), $\mathrm{N}(3)-\mathrm{Li}(1)-\mathrm{N}(1)$ 124.6(2), N(4)-Li(1)-N(2) 139.9(2), N(1)-Li(1)-N(2) 72.1(1). 
The closest synthetic analogy to the reaction producing $\mathbf{4}$ and $\mathbf{5}$ is Veith's report ${ }^{[11 \mathrm{a}]}$ of the 1,3-diaza-2-silacyclopentene $\mathbf{6 a}$ as it involves dilithiation of $t \mathrm{BuN}(\mathrm{H}) \mathrm{CH}_{2} \mathrm{CH}_{2} \mathrm{~N}(\mathrm{H}) t \mathrm{Bu}$ (Scheme 2). Distinct from our method, the anticipated dianionic diamide was not isolated but trapped in situ with a dichlorosilane to generate the neutral, as opposed to our anionic, heterocyclopentene. Oddly, 6a formed only in highly concentrated solutions, ${ }^{[11 \mathrm{a}]}$ whereas dilute solutions, ${ }^{[11 \mathrm{~b}]}$ more akin to that employed in our study gave an alternative heterocyclopentane product $\mathbf{6 b}$. Veith conceded that the reason for the double hydrogen abstraction from the ethylene backbone in forming 6a was unclear. In theory $\mathbf{4}$ and $\mathbf{5}$ having potentially labile metal centers primed for participation in salt metathesis reactions could be regarded as intermediates in conversions of this type.
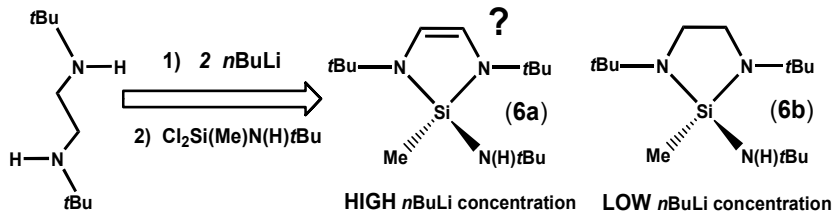

Scheme 2. Veith's reaction of $t \mathrm{BuN}(\mathrm{H}) \mathrm{CH}_{2} \mathrm{CH}_{2} \mathrm{~N}(\mathrm{H}) t \mathrm{Bu}$ with $n \mathrm{BuLi}$ and further trapping with a dichlorosilane.

A repeat reaction of $t \mathrm{Bu}_{2} \mathrm{Zn}, n \mathrm{BuLi}$, and the diamine in the additional presence of the bulky ketone $(t \mathrm{Bu})_{2} \mathrm{C}=\mathrm{O}$ (Scheme 3) may have provided an initial clue to the mechanism behind the formation of 4. An NMR analysis of the crude reaction revealed a complicated mixture of products, ${ }^{[5]}$ among which, significantly, 4 and the lithium alkoxide $\left[\left\{\mathrm{Bu}_{2} \mathrm{C}(\mathrm{H}) \mathrm{OLi}\right\}_{4}\right], 7$, were clearly identified. The existence of 7 , the result of a hydride addition to the electrophilic $C=\mathrm{O}$ of the ketone, hints at the possible participation of an intermediate hydride species in the $\mathrm{N}-\mathrm{CH}_{2}-$ $\mathrm{CH}_{2}-\mathrm{N}$ to $\mathrm{N}-\mathrm{CH}=\mathrm{CH}-\mathrm{N}$ transformation. While the source of the hydride cannot be ascertained with absolute certainty at this juncture, we could straightforwardly rule out that it was coming from either $n \mathrm{BuLi}$ or $t \mathrm{Bu}_{2} \mathrm{Zn},{ }^{[12]}$ suggesting that it originates from the ethylene backbone of the diamine. With monoamine dibenzylamine $\left[\left(\mathrm{PhCH}_{2}\right)_{2} \mathrm{NH}\right]$, it has been postulated ${ }^{[13]}$ that metalation of $\mathrm{N}-H$, followed by $\beta$-hydride elimination of " $\mathrm{M}^{+} \mathrm{H}^{-}$" and its subsequent metalation of the remaining $\mathrm{NCH}_{2}$ unit (accompanied by $\mathrm{H}_{2}$ evolution) accounts for the formation of the 2-aza-allyl anion $\left[\{\mathrm{PhC}(\mathrm{H})=\mathrm{N}-\mathrm{C}(\mathrm{H}) \mathrm{Ph}\}^{-}\right] . \quad$ Similar metalation $/ \beta$-hydride elimination/re-metalation sequences could be operating in the reaction yielding 4 . For completeness, isolated 7 was also crystallographically characterized. Its molecular structure (see the Supporting Information) is tetrameric with a heterocubane $\left[\left(\mu_{3}-\mathrm{OR}\right)_{4} \mathrm{Li}_{4}\right]$ core of a type well documented for lithium alkoxides. ${ }^{[14]}$ These precedents commonly possess additional donor ligands at the $\mathrm{Li}$ corners, so 7 belongs to a rarer type $^{[15]}$ wherein the large bulk of the $\mathrm{R}$ group promotes steric saturation of $\mathrm{Li}$ at the expense of electronic saturation.

Noting that the $\mathrm{N}-\mathrm{CH}_{2}-\mathrm{CH}_{2}-\mathrm{N}$ to $\mathrm{N}-\mathrm{CH}=\mathrm{CH}-\mathrm{N}$ transformation outlined here for certain will not involve redox processes like that reported by Brookhart ${ }^{[16]}$ for late transition metal catalysed intramolecular dehydrogenations, in future work we plan to carry out a comprehensive computational study to elucidate the mechanism of this transformation with emphasis on the precise role of the lithium-zinc co-operativity.

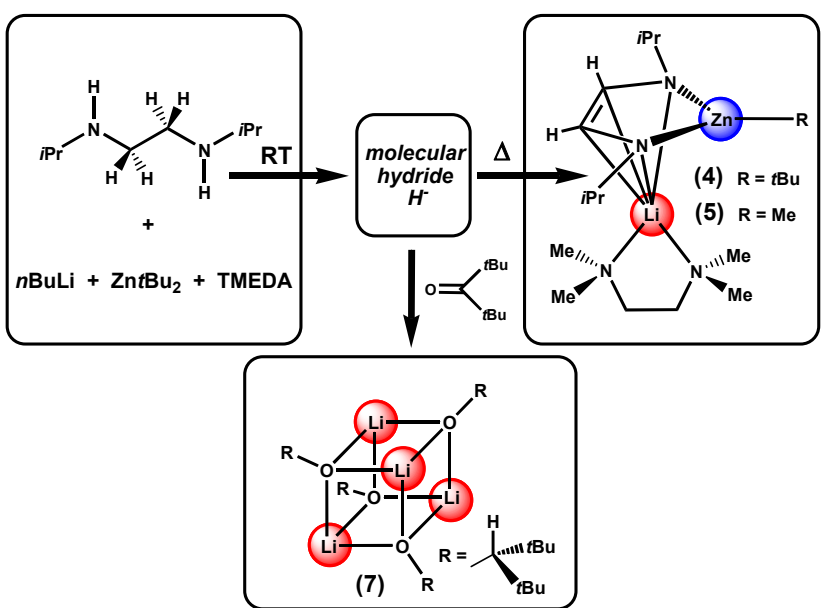

Scheme 3. Reaction of $\operatorname{iPrN}(\mathrm{H}) \mathrm{CH} 2 \mathrm{CH} 2 \mathrm{~N}(\mathrm{H}) \mathrm{Pr}$ with a nBuLi/R $2 \mathrm{Zn} / \mathrm{TMEDA}$ synergic mixture to form $\mathbf{4}$ or $\mathbf{5}$ via a putative intermediate hydride which can also be trapped with a ketone to generate a lithium alkoxide.

\section{Experimental Section}

General methods: All reactions and manipulations were carried out in an atmosphere of dry pure argon gas using standard Schlenk and glovebox techniques. $n$-Hexane was distilled from sodium-benzophenone. NMR spectra were recorded on a Bruker AVANCE 400 NMR spectrometer, operating at $400.13 \mathrm{MHz}$ for ${ }^{1} \mathrm{H}, 155.50$ $\mathrm{MHz}$ for ${ }^{7} \mathrm{Li}$ and $100.62 \mathrm{MHz}$ for ${ }^{13} \mathrm{C}$. Data for X-ray crystal structure determination were obtained with a Oxford Diffraction Gemini diffractometer using Mo-K $\alpha(\lambda=$ $0.71073 \AA$; compounds 5 and 7) and $\mathrm{Cu}-\mathrm{K} \alpha(\lambda=1.54180 \AA$; compounds 1 and $\mathbf{3})$ graphite monochromated radiations. Satisfactory elemental analyses of the compounds could not be obtained due to their high air- and moisture-sensitive nature.

Synthesis of 1: A Schlenk tube was charged with $4 \mathrm{mmol}(0.72 \mathrm{~g})$ of $\mathrm{Zn}^{t} \mathrm{Bu}_{2}$ which was dissolved in $20 \mathrm{~mL}$ of hexane and one equivalent of $i \operatorname{Pr}(\mathrm{H}) \mathrm{NCH}_{2} \mathrm{CH}_{2} \mathrm{CH}_{2} \mathrm{~N}(\mathrm{H}) i \operatorname{Pr}(4 \mathrm{mmol}, 0.72 \mathrm{~mL})$ was added via syringe. The resultant colourless solution was allowed to stir overnight at RT and heated at reflux temperature for $10 \mathrm{~min}$. To aid crystallisation the solution was concentrated under reduced pressure to a final volume of $2-3 \mathrm{~mL}$ and, after standing overnight at $-27^{\circ} \mathrm{C}$, colourless crystals of $\mathbf{1}$ (suitable for X-ray crystallographic analysis) were obtained $(0.20 \mathrm{~g}, 15 \%)$. The low crystalline yield obtained for $\mathbf{1}$ is just a reflection of its high solubility, being the overall reaction yield almost quantitative as determined by NMR spectroscopic analyses of both 1 and reaction filtrates. ${ }^{1} \mathrm{H}$ NMR $(400.13 \mathrm{MHz}$, $\mathrm{C}_{6} \mathrm{D}_{6}, 293 \mathrm{~K}$ ): $\delta=2.62(\mathrm{~m}, 2 \mathrm{H}, \mathrm{CH}, i \mathrm{Pr}), 2.02\left(\mathrm{~m}, 4 \mathrm{H}, \mathrm{CH}_{2}\right), 1.34\left(\mathrm{~s}, 18 \mathrm{H}, \mathrm{CH}_{3}\right.$, $t \mathrm{Bu}), 0.90\left(\mathrm{~d}, J=5.2 \mathrm{~Hz}, 12 \mathrm{H}, \mathrm{CH}_{3}, i \operatorname{Pr}\right), 0.85(\mathrm{~s}, \mathrm{br}, 2 \mathrm{H}, \mathrm{N} H) .{ }^{13} \mathrm{C}\left\{{ }^{1} \mathrm{H}\right\} \mathrm{NMR}$ $\left(100.62 \mathrm{MHz}, \mathrm{C}_{6} \mathrm{D}_{6}, 293 \mathrm{~K}\right): \delta=49.5(\mathrm{CH}, i \mathrm{Pr}), 47.2\left(\mathrm{CH}_{2}\right), 35.8\left(\mathrm{CH}_{3}, t \mathrm{Bu}\right), 23.1$ $\left(\mathrm{CH}_{3}, i \mathrm{Pr}\right), 19.9\left(\mathrm{C}\left(\mathrm{CH}_{3}\right), i \mathrm{Pr}\right)$.

Crystallisation of 3: $1.25 \mathrm{~mL}(2 \mathrm{mmol}) n$ BuLi was added dropwise to a solution of $0.36 \mathrm{~mL}(2 \mathrm{mmol}) \operatorname{DPEDA}\left(\mathrm{H}_{2}\right)$ in $10 \mathrm{~mL}$ hexane at $0{ }^{\circ} \mathrm{C}$. This temperature was maintained as $0.3 \mathrm{~mL}$ ( $2 \mathrm{mmol}$ ) TMEDA and a solution of $0.36 \mathrm{~g} \mathrm{(2} \mathrm{mmol)} t \mathrm{Bu}_{2} \mathrm{Zn}$ in $10 \mathrm{~mL}$ hexane were added giving a pale yellow solution with some white solid. This solution was stored immediately at $-27{ }^{\circ} \mathrm{C}$ giving a crop of colourless crystals suitable for X-ray crystallographic analysis corresponding to complex 3 . Attempts to characterise by NMR spectroscopy the kinetic product 3 resulted unsuccessful due to its high thermal instability.

Synthesis of 4: $1.25 \mathrm{~mL}(2 \mathrm{mmol}) n \mathrm{BuLi}$ was added dropwise to a solution of 0.36 $\mathrm{mL}(2 \mathrm{mmol}) \operatorname{DPEDA}\left(\mathrm{H}_{2}\right)$ in $10 \mathrm{~mL}$ hexane at $0{ }^{\circ} \mathrm{C}$. This temperature was maintained as $0.3 \mathrm{~mL}$ ( $2 \mathrm{mmol}$ ) TMEDA and a solution of $0.36 \mathrm{~g} \mathrm{(2} \mathrm{mmol)} t \mathrm{Bu}_{2} \mathrm{Zn}$ in $10 \mathrm{~mL}$ hexane were added giving a pale yellow solution with some white solid. 
This solution was refluxed for 2 hours producing a bright orange solution. Storing the solution at $-70{ }^{\circ} \mathrm{C}$ gave a crop of yellow crystals of $\mathbf{4}$ which were isolated in a $38.9 \%(0.30 \mathrm{~g})$ crystalline yield. ${ }^{1} \mathrm{H}$ NMR $\left(400.13 \mathrm{MHz}, \mathrm{C}_{6} \mathrm{D}_{6}, 300 \mathrm{~K}\right): \delta(\mathrm{ppm})=$ 5.83 (s, $2 \mathrm{H}, \mathrm{CH}, \mathrm{CH}=\mathrm{CH}$ ), 3.48 (m, $2 \mathrm{H}, \mathrm{CH}, i \mathrm{Pr}), 1.81$ (s, $12 \mathrm{H}, \mathrm{CH}_{3}$, TMEDA), 1.60 (s, $\left.9 \mathrm{H}, \mathrm{CH}_{3}, t \mathrm{Bu}\right), 1.58$ (s, $4 \mathrm{H}, \mathrm{CH}_{2}$, TMEDA), 1.40 (d, $J=6.3 \mathrm{~Hz}, 6 \mathrm{H}, \mathrm{CH}_{3}$, $i \operatorname{Pr}), 1.32\left(\mathrm{~d}, J=6.3 \mathrm{~Hz}, 6 \mathrm{H}, \mathrm{CH}_{3}, i \mathrm{Pr}\right) .{ }^{13} \mathrm{C}\left\{{ }^{1} \mathrm{H}\right\} \mathrm{NMR}\left(100.62 \mathrm{MHz}, \mathrm{C}_{6} \mathrm{D}_{6}, 300 \mathrm{~K}\right)$ : $\delta(\mathrm{ppm})=116.3(\mathrm{CH}, \mathrm{CH}=\mathrm{CH}), 56.0\left(\mathrm{CH}_{2}, \mathrm{TMEDA}\right), 52.7(\mathrm{CH}, i \mathrm{Pr}), 45.6\left(\mathrm{CH}_{3}\right.$,

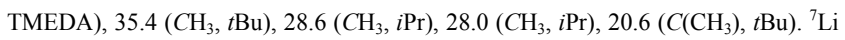
$\left(155.50 \mathrm{MHz}, \mathrm{C}_{6} \mathrm{D}_{6}, 300 \mathrm{~K}\right): \delta(\mathrm{ppm})=-2.40$.

\section{Acknowledgements}

We gratefully acknowledge the generous support of the UK EPSRC (grant award no. EP/F063733/1) and the Royal Society/Wolfson Foundation (research merit award to R.E.M). We also thank our colleague Dr Eva Hevia for many enlightening discussions. This research was also sponsored by a Marie Curie Intra European Fellowship within the $7^{\text {th }}$ European Community Framework Programme (for P.G.A.).

\section{Keywords: amines $\cdot$ diamines $\cdot$ hydride $\cdot$ lithium $\cdot$} metallacycle $\cdot$ synergy $\cdot$ zinc

[1] For recent reviews on alkali metal zincates and their applications in metalation applications, see : a) R. E. Mulvey, Organometallics 2006, 25, 1060; b) R. E. Mulvey, F. Mongin, M. Uchiyama, Y. Kondo, Angew. Chem. 2007, 119, 3876; Angew. Chem. Int. Ed. 2007, 46, 3802; c) R.E. Mulvey, Acc. Chem. Res. 2009, 42, 743

[2] a) J.-M. L'Helgoual'ch, G. Bentabed-Ababsa, F. Chevallier, M. Yonehara, M. Uchiyama, A. Derdour, F. Mongin, Chem. Commun. 2008, 5375; b) G. Dayaker, A. Sreeshailam, F. Chevallier, T. Roisnel, P. R. Krishna, F. Mongin, Chem. Commun. 2010, 46, 2862; c) K. Snegaroff, J.-M. L'Helgoual'ch, G. Bentabed-Ababsa, T. T. Nguyen, F. Chevallier, M. Yonehara, M. Uchiyama, A. Derdour, F. Mongin, Chem. Eur. J. 2009, 15, 10280; d) A. Seggio, G. Priem, F. Chevallier, F. Mongin, Synthesis 2009, 3617; e) A. Seggio, M.-I. Lannou, F. Chevallier, D. Nobuto, M. Uchiyama, S. Golhen, T. Roisnel, F. Mongin, Chem. Eur. J. 2007, 13, 9982; f) A. Seggio, F. Chevallier, M. Vaultier, F. Mongin, J. Org. Chem. 2007, 72, 6602; g) J.-M. L'Helgoual'ch, A. Seggio, F. Chevallier, M. Yonehara, E. Jeanneau, M. Uchiyama, F. Mongin, J. Org. Chem. 2008, 73, 177; h) M. Uchiyama, Y. Matsumoto, S. Usui, Y. Hashimoto, K. Morokuma, Angew. Chem. 2007, 119, 944; Angew. Chem., Int. Ed. 2007, 46, 926; i) M. Uchiyama, Y. Kobayashi, T. Furuyama, S. Nakamura, Y. Kajihara, T. Miyoshi, T. Sakamoto, Y. Kondo, K. Morokuma, J. Am. Chem. Soc. 2008, 130, 472; j) Y. Kondo, J. V. Morey, J. C. Morgan, H. Naka, D. Nobuto, P. R. Raithby, M. Uchiyama, A. E. H. Wheatley, J. Am. Chem. Soc. 2007, 129, 12734; k) F. Garcia, M. McPartlin, J. V. Morey, D. Nobuto, Y. Kondo, H. Naka, M. Uchiyama, A. E. H. Wheatley, Eur. J. Org. Chem. 2008, 644; 1) W. Clegg, D. V. Graham, E. Herd, E. Hevia, A. R. Kennedy, M. D. McCall, L. Russo, Inorg. Chem. 2009, 48, 5320; m) E. Hevia, A. R. Kennedy, J. Klett, M. D. McCall, Chem. Commun. 2009, 3240; n) D. R. Armstrong, E. Herd, D. V. Graham, E. Hevia, A. R. Kennedy, W. Clegg, L. Russo, Dalton Trans. 2008, 1323; o) D. R. Armstrong, A. M. Drummond, L. Balloch, D. V. Graham, E. Hevia, A. R. Kennedy, Organometallics 2008, 27, 5860; p) W. Clegg, S. H. Dale, E. Hevia, L. M. Hogg, G. W. Honeyman, R. E. Mulvey, C. T. O'Hara, Angew. Chem. 2006, 118, 6698; Angew. Chem., Int. Ed. 2006, 45, 6548; q) D. R. Armstrong, J. Garcia-Alvarez, D. V. Graham, G. W. Honeyman, E. Hevia, A. R. Kennedy, R. E. Mulvey, Chem. Eur. J. 2009, 15, 3800; r) D. R. Armstrong, W. Clegg, S. H. Dale, E. Hevia, L. M. Hogg, G.
W. Honeyman, R. E. Mulvey, Angew. Chem. 2006, 118, 3859; Angew. Chem., Int. Ed. 2006, 45, 3775; s) D. R. Armstrong, L. Balloch, W. Clegg, S. H. Dale, P. Garcia-Alvarez, E. Hevia, L. M. Hogg, A. R. Kennedy, R. E. Mulvey, C. T. O'Hara, Angew. Chem. 2009, 121, 8831; Angew. Chem., Int. Ed. 2009, 48, 8675; t) P. C. Andrikopoulos, D. R. Armstrong, H. R. L. Barley, W. Clegg, S. H. Dale, E. Hevia, G. W. Honeyman, A. R. Kennedy, R. E. Mulvey, J. Am. Chem. Soc. 2005, 127, 6184.

[3] a) S. Wunderlich, P. Knochel, Chem. Commun. 2008, 6387; b) M. Mosrin, G. Monzon, T. Bresser, P. Knochel, Chem. Commun. 2009, 5615; c) S. H. Wunderlich, C. J. Rohbogner, A. Unsinn, P. Knochel, Org. Process Res. Dev. 2010, 14, 339; d) S. Wunderlich, P. Knochel, Org. Lett. 2008, 10 , 4705; e) M. Mosrin, P. Knochel, Chem. Eur. J. 2009, 15, 1468; f) M Mosrin, P. Knochel, Org. Lett. 2009, 11, 1837; g) Z. Dong, G. C. Clososki, S. H. Wunderlich, A. Unsinn, J. Li, P. Knochel, Chem. Eur. J. 2009, 15, 457; h) E. Hevia, J. Z. Chua, P. Garcia-Alvarez, A. R. Kennedy, M. D. McCall, Proc. Natl. Acad. Sci. U. S. A. 2010, 107, 5294.

[4] M. G. Gardiner, C. L. Raston, Inorg.Chem. 1996, 35, 4047.

[5] See Supporting Information for full experimental and crystallographic details.

[6] X.-J. Yang, J. Yu, Y. Liu, Y. Xie, H. F. Schaefer, Y. Liang, B. Wu, Chem.Commun. 2007, 2363.

[7] E. Rijnberg, J. Boersma, J. T. B. H. Jastrzebski, M. T. Lakin, A. L. Spek, G. Van Koten, Chem.Commun. 1995, 1839.

[8] Y. Liu, S. Li, X.-J. Yang, P. Yang, B. Wu, J. Am. Chem. Soc. 2009, 131, 4210.

[9] E. S. Schmidt, N. W. Mitzel, H. Schmidbaur, Z. Naturforsch., B: Chem. Sci. 2001, 56, 937.

[10] S. Aldridge, R. J. Baker, N. D. Coombs, C. Jones, R. P. Rose, A. Rossin, D. J. Willock, Dalton Trams. 2006, 3313.

[11] a) M. Veith, B. Schillo, V. Huch, Angew. Chem. 1999, 111, 131; Angew. Chem. Int. Ed. 1999, 38, 182; b) M. Veith, A. Rammo, Z. Anorg. Allg. Chem. 1997, 623, 861 .

[12] Note that in the synthesis of $\mathbf{4}$ the order of addition of the metal reagents to the diamine is not crucial, as $t \mathrm{Bu}_{2} \mathrm{Zn}$ or $n \mathrm{BuLi}$ can be introduced first. In the latter case all the $n \mathrm{BuLi}$ is consumed in forming a lithium amide before the zinc reagent is applied. This rules out the possibility that in the ketone reaction the hydride comes from the lithium reagent, a point confirmed by a control reaction between $n \mathrm{BuLi}$ and the ketone which did not produce a reduction product. The other possibility that $\mathrm{H}^{-}$was coming from $t \mathrm{Bu}$ groups on zinc was also ruled out as the reaction proved repeatable with $\mathrm{Me}_{2} \mathrm{Zn}$ forming 5 .

[13] a) P. C. Andrews, D. R. Armstrong, D. R. Baker, R. E. Mulvey, W. Clegg, L. Horsburgh, P. A. O'Neil, D. Reed, Organometallics 1995, 14, 427; b) P. C. Andrews, P. J. Duggan, G. D. Fallon, T. D. McCarthy, A. C. Peatt, $J$ Chem. Soc. Dalton Trans. 2000, 2505; c) P. C. Andrews, P. J. Duggan, M. Maguire, P. J. Nichols, Chem.Commun. 2001, 53.

[14] See for example: a) T. J. Boyle, D. M. Pedrotty, T. M. Alam, S. C. Vick, M. A. Rodriguez, Inorg. Chem. 2000, 39, 5133; b) T. J. Boyle, T. M. Alam, K. P. Peters, M. A. Rodriguez, Inorg. Chem. 2001, 40, 6281.

[15] See for example: a) U. Piarulli, D. N. Williams, C. Floriani, G. Gervasio, D. Viterbo, Chem. Commun. 1994, 1409; b) A. Reisinger, N. Trapp, I. Krossing, Organometallics 2007, 26, 2096.

[16] a) M. M. Diaz-Requejo, D. Disalvo, M. Brookhart, J. Am. Chem. Soc. 2003, 125, 2038; b) A. D. Bolig, M Brookhart, J. Am. Chem. Soc. 2007, 129 , 14544.

Received: ((will be filled in by the editorial staff))

Revised: ((will be filled in by the editorial staff)) Published online: ((will be filled in by the editorial staff)) 
Entry for the Table of Contents (Please choose one layout only)

\section{Layout 1:}

Metal-Mediated Synthesis

Ross Campbell, Pablo García-

Álvarez, * Alan R. Kennedy, and

Robert E. Mulvey*

Page - Page

Synergic Transformation of an Ethylenediamine to a Lithium 1, 3-Diaza-2-zincacyclopentene via an Alkyllithium/Bis(alkyl)zinc Mixture
Deadly Duo: Four bonds in total, two $\mathrm{N}-\mathrm{H}$ and two C-H bonds have been cleaved from a neutral secondary diamine through the cooperative effects of a lithium alkyl-zinc bisalkyl coalition aided by TMEDA to generate a dianionic diazaethene. 


\title{
Supporting Information
}

\section{Cleave and Capture Chemistry: Synergic Fragmentation of THF}

\author{
Robert E. Mulvey ${ }^{*}$, Victoria L. Blair ${ }^{1}$, William Clegg $^{2}$, Alan R. Kennedy ${ }^{1}$, Jan Klett $^{1}$, \\ Luca Russo $^{2}$ \\ 1 WestCHEM, Department of Pure and Applied Chemistry, University of Strathclyde, \\ Glasgow, G1 1XL, U.K. \\ ${ }^{2}$ School of Chemistry, Newcastle University, Newcastle upon Tyne, NE1 7RU, U.K. \\ *e-mail: r.e.mulvey@strath.ac.uk
}

\section{Synthesis and Characterisation of Compounds 3, 4, 5 and 6.}

General Methods. $n$-Hexane and THF were distilled from sodium-benzophenone, TMEDA was distilled from $\mathrm{CaH}_{2}$. All synthetic work was carried out under an inert argon atmosphere using standard Schlenk and glove box techniques. ${ }^{1} \mathrm{H}$ and ${ }^{13} \mathrm{C}$ NMR spectra were recorded on either a Bruker AV 400 or Bruker DPX 400 and were referenced to the resonances of the deuterated solvents used. Bis(trimethylsilylmethyl)magnesium $\mathrm{Mg}\left(\mathrm{CH}_{2} \mathrm{SiMe}_{3}\right)_{2}{ }^{[1]}$ and bis(trimethylsilylmethyl)manganese $\mathrm{Mn}\left(\mathrm{CH}_{2} \mathrm{SiMe}_{3}\right)_{2}{ }^{[2,3]}$ were prepared according to literature procedures. The crude bis(trimethylsilylmethyl)magnesium was also purified via sublimation at $175^{\circ} \mathrm{C}\left(\sim 10^{-2}\right.$ torr $)$ to furnish pure $\mathrm{Mg}\left(\mathrm{CH}_{2} \mathrm{SiMe}_{3}\right)_{2}$.

Experimental Crystallography. Measurements were made either with an Enraf Nonius Kappa Diffractometer (4) or an Oxford Diffraction Xcalibur Sapphire system (5 and 6). All structures were refined to convergence against $F^{2}$ using programs from the SHELX family. ${ }^{[4]}$ Selected parameters are summarized in the text and full details given in the supplementary cif files. 4 and 5 are well ordered and routinely modeled compounds. Although otherwise isostructural with $\mathbf{5}$, the structure of compound $\mathbf{6}$ appears somewhat disordered in the region of the captured dianion. After several trial calculations, the best model described a species with an $80 \%$ occupied butadiene site and a $20 \%$ occupied benzene site (both twice deprotonated). Whether the benzene fragment derives from an impurity in the starting materials or is formed in situ, possibly via further reaction of the butadiene fragments, is unknown. CCDC-756447 (4), CCDC-756448 (5) and CCDC-756449 (6) contain the supplementary crystallographic data for this publication. These data can be obtained free of 
charge at www.ccdc.cam.ac.uk/conts/retrieving.html (or from the Cambridge Crystallographic Data Centre, 12 Union Road, Cambridge CB2 1EZ, UK; Fax: + 44-1223-336-033; e-mail: deposit@ccdc.cam.ac.uk).

\section{Synthesis of $\left[\mathrm{Na}_{2} \mathrm{Mg}_{2}(\mathrm{TMP})_{4}(\mathrm{O})\right], 3$ and $\left[\{(\mathrm{TMEDA}) \mathrm{Na}(\mu-\mathrm{TMP})\}_{2}\left\{1,4-[\mathrm{Mg}(\mathrm{TMP})]_{2^{-}}\right.\right.$}

$\mathbf{C}_{4} \mathbf{H}_{4}$ \}], 5: TMPH $(0.34 \mathrm{~mL}, 2.0 \mathrm{mmol})$ was added to a suspension of $\mathrm{BuNa}(0.08 \mathrm{~g}, 1.0$ mmol) in dry n-hexane $(20 \mathrm{~mL})$ and the resultant mixture was allowed to stir at room temperature for $1 \mathrm{~h} . \mathrm{Mg}\left(\mathrm{CH}_{2} \mathrm{SiMe}_{3}\right)_{2}(0.20 \mathrm{~g}, 1.0 \mathrm{mmol})$ and TMEDA $(0.15 \mathrm{~mL}, 1.0 \mathrm{mmol})$ was added to give a light yellow solution. Next, THF $(0.08 \mathrm{~mL}, 1.0 \mathrm{mmol})$ was added and the colourless solution was gently heated for 5 minutes. Upon cooling to room temperature large colourless needle crystals of 5 were deposited $(0.23 \mathrm{~g}, 48.9 \%)$. The mother liquor was subsequently further concentrated under vacuum and upon standing at room temperature colourless plate crystals of 3 were deposited (0.14 g, $41.7 \%$ ). mp (for 3): $202{ }^{\circ} \mathrm{C}$ (decomposition); $\mathrm{mp}$ (for 5): $186^{\circ} \mathrm{C}$ (decomposition).

NMR data for 3: ${ }^{1} \mathrm{H}$ NMR (400.03 MHz, $\mathrm{d}_{6}$-benzene, $\left.300 \mathrm{~K}\right): \delta 1.98$ (m, $\left.1 \mathrm{H}, \gamma-\mathrm{CH}_{2}, \mathrm{TMP}\right)$, 1.74 (d (br), 3H, $\gamma-\mathrm{CH}_{2}$, TMP \& $\left.\beta-\mathrm{CH}_{2}, \mathrm{TMP}\right), 1.47$ (s, 6H, $\left.\mathrm{CH}_{3} \mathrm{TMP}\right), 1.26$ (s, 6H, $\mathrm{CH}_{3}$ TMP), 1.00 ppm (m (br), 2H, $\left.\beta-\mathrm{CH}_{2}, \mathrm{TMP}\right) .{ }^{13} \mathrm{C}$ NMR (100.59 MHz, $\mathrm{d}_{6}$-benzene, $\left.300 \mathrm{~K}\right): \delta$ 51.80 ( $\alpha$-C-TMP), 43.3 ( $\left.\beta-\mathrm{CH}_{2}, \mathrm{TMP}\right), 39.1\left(\mathrm{CH}_{3}-\mathrm{TMP}\right), 34.3\left(\mathrm{CH}_{3}-\mathrm{TMP}\right), 19.9 \mathrm{ppm}\left(\gamma-\mathrm{CH}_{2}\right.$, TMP). NMR data for 5: ${ }^{1} \mathrm{H}$ NMR (400.03 MHz, $\mathrm{d}_{6}$-benzene, $\left.300 \mathrm{~K}\right): \delta 6.75\left(\mathrm{~s}, 4 \mathrm{H}, \mathrm{C}_{4} H_{4}\right)$, 2.18 (s, 8H, $\left.\mathrm{CH}_{2}, \mathrm{TMEDA}\right), 2.06$ (s, 24H, $\left.\mathrm{CH}_{3}, \mathrm{TMEDA}\right), 1.68$ (s (br), 48H, $\left.\mathrm{CH}_{3} \mathrm{TMP}\right), 1.49$ ppm ( s (br), 24H, $\gamma-\mathrm{CH}_{2}$, TMP \& $\beta-\mathrm{CH}_{2}$, TMP). ${ }^{1} \mathrm{H}$ NMR (400.03 MHz, $\left.\mathrm{d}_{8}-\mathrm{THF}, 300 \mathrm{~K}\right): \delta$ $6.50\left(\mathrm{~m}, 2 \mathrm{H}, \mathrm{C}_{4} \mathrm{H}_{4}\right), 6.36\left(\mathrm{~m}, 2 \mathrm{H}, \mathrm{C}_{4} \mathrm{H}_{4}\right), 2.30$ (s, 8H, $\mathrm{CH}_{2}$, TMEDA), 2.15 (s, 24H, $\mathrm{CH}_{3}$, TMEDA), 1.67 (m, 8H, $\left.\gamma-\mathrm{CH}_{2}, \mathrm{TMP}\right), 1.24$ (s (br), 48H, $\left.\mathrm{CH}_{3} \mathrm{TMP}\right), 1.16$ ppm ( m (br), 16H, $\left.\beta-\mathrm{CH}_{2}, \mathrm{TMP}\right) .{ }^{13} \mathrm{C}$ NMR $\left(100.59 \mathrm{MHz}, \mathrm{d}_{8} \mathrm{THF}, 300 \mathrm{~K}\right): 163.32\left(\mathrm{C}_{\mathrm{B}}, C_{4} \mathrm{H}_{4}\right), 154.99\left(\mathrm{C}_{\mathrm{A}}\right.$, $\left.\mathrm{C}_{4} \mathrm{H}_{4}\right), 58.94\left(\mathrm{CH}_{2}\right.$-TMEDA), 52.62 ( $\alpha$-C-TMP), 46.23 ( $\mathrm{CH}_{3}$-TMEDA), $42.57\left(\beta-\mathrm{CH}_{2}, \mathrm{TMP}\right)$, $35.82\left(\mathrm{CH}_{3}-\mathrm{TMP}\right), 20.75 \mathrm{ppm}\left(\gamma-\mathrm{CH}_{2}, \mathrm{TMP}\right)$.

Crystal data for 5: $\mathrm{C}_{52} \mathrm{H}_{108} \mathrm{Mg}_{2} \mathrm{~N}_{8} \mathrm{Na}_{2}, M_{r}=940.06 \mathrm{~g} / \mathrm{mol}$, monoclinic, space group $\mathrm{P} 2{ }_{1} / \mathrm{n}, a=$ 8.2736(3), $b=21.4955(8), c=16.5688(6) \AA, \beta=90.708(4)^{\circ}, V=2946.46(19) \AA^{3}, Z=2, \lambda=$ $0.71073 \AA, \mu=0.094 \mathrm{~mm}^{-1}, T=123 \mathrm{~K} ; 31164$ reflections, 7797 unique, $R_{\text {int }} 0.0273$; final refinement to convergence on $F^{2}$ gave $R=0.0378\left(F, 5648\right.$ obs. data only) and $R_{\mathrm{W}}=0.1036$ $\left(F^{2}\right.$, all data), GOF $=1.069$. 


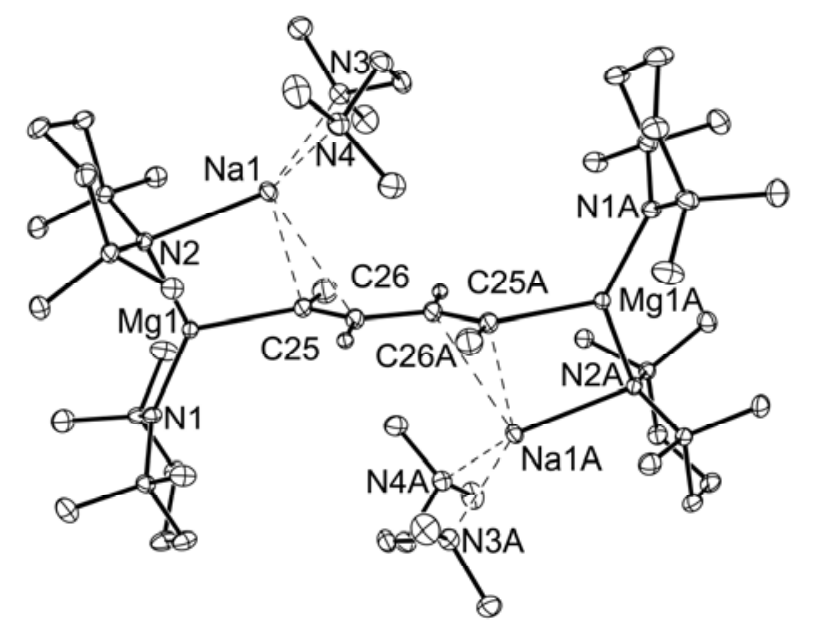

Figure S1. Molecular structure of 5 (on the $30 \%$ probability level). Selected hydrogen atoms have been omitted for clarity.

Synthesis [\{(TMEDA)Na( $\mu$-TMP) $\left.\}_{2}\left\{1,4-[M g(T M P)]_{2}-C_{4} \mathbf{D}_{4}\right\}\right], \mathbf{5}\left(\mathbf{d}^{4}\right):$ TMPH $(0.34 \mathrm{~mL}, 2.0$ mmol) was added to a suspension of $\mathrm{BuNa}(0.08 \mathrm{~g}, 1.0 \mathrm{mmol})$ in dry n-hexane $(20 \mathrm{~mL})$ and the resultant mixture was allowed to stir at room temperature for $1 \mathrm{~h} . \mathrm{Mg}\left(\mathrm{CH}_{2} \mathrm{SiMe}_{3}\right)_{2}(0.20 \mathrm{~g}$, $1.0 \mathrm{mmol})$ and TMEDA $(0.15 \mathrm{~mL}, 1.0 \mathrm{mmol})$ was added to give a light yellow solution. Next, $\mathrm{d}_{8}$-THF $(0.08 \mathrm{~mL}, 1.0 \mathrm{mmol})$ was added and the colourless solution was gently heated for 5 minutes. Upon cooling to room temperature large colourless needle crystals of $\mathbf{5}\left(\mathbf{d}^{\mathbf{4}}\right)$ were deposited (0.18 g, 38.2\%).

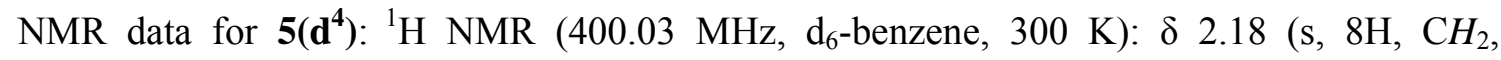
TMEDA), 2.06 (s, 24H, $\mathrm{CH}_{3}$, TMEDA), 1.68 (s (br), 48H, $\mathrm{CH}_{3}$ TMP), 1.49 ppm (s (br), 24H, $\left.\gamma-\mathrm{CH}_{2}, \mathrm{TMP} \& \beta-\mathrm{CH}_{2}, \mathrm{TMP}\right)$.

\section{Synthesis of $\left[\mathrm{Na}_{2} \mathrm{Mn}_{2}(\mathrm{TMP})_{4}(\mathrm{O})\right], 4$ and $\left[\{(\mathrm{TMEDA}) \mathrm{Na}(\mu-\mathrm{TMP})\}_{2}\left\{1,4-[\mathrm{Mn}(\mathrm{TMP})]_{2}-\right.\right.$}

$\left.\mathbf{C}_{4} \mathbf{H}_{4}\right\}$ ], 6: TMPH $(0.34 \mathrm{~mL}, 2.0 \mathrm{mmol})$ was added to a suspension of $\mathrm{BuNa}(0.08 \mathrm{~g}, 1.0$ mmol) in dry $\mathrm{n}$-hexane $(20 \mathrm{~mL})$ and the resultant mixture was allowed to stir at room temperature for $1 \mathrm{~h} . \mathrm{Mn}\left(\mathrm{CH}_{2} \mathrm{SiMe}_{3}\right)_{2}(0.23 \mathrm{~g}, 1.0 \mathrm{mmol})$ and TMEDA $(0.15 \mathrm{~mL}, 1.0 \mathrm{mmol})$ was added to give a light orange solution. Next, THF $(0.08 \mathrm{~mL}, 1.0 \mathrm{mmol})$ was added and the solution allowed to stir at room temperature for $12 \mathrm{hrs}$. The red solution was filtered and concentrated slightly under vacuum. Allowing the solution to stand at room temperature for 1 week afforded red/orange needle crystals of 6 to form $(0.25 \mathrm{~g}, 49.9 \%)$. The mother liquor was further concentrated in vacuum to furnish light pink plate crystals of $4(0.16 \mathrm{~g}, 43.6 \%)$. mp (for 4): $192{ }^{\circ} \mathrm{C}$ (decomposition); mp (for 6): $183^{\circ} \mathrm{C}$ (decomposition). 
Crystal data for 4: $\mathrm{C}_{36} \mathrm{H}_{72} \mathrm{Mn}_{2} \mathrm{~N}_{4} \mathrm{Na}_{2} \mathrm{O}, M_{r}=732.84 \mathrm{~g} / \mathrm{mol}$, monoclinic, space group $\mathrm{P} 2_{1} / \mathrm{n}, a=$ 11.985(2), $b=11.542(2), c=15.364(2) \AA, \beta=107.15(3){ }^{\circ}, V=2030.8(7) \AA^{3}, Z=2, \lambda=$ $0.71073 \AA, \mu=0.674 \mathrm{~mm}^{-1}, T=150 \mathrm{~K} ; 19712$ reflections, 3539 unique, $R_{\text {int }} 0.0401$; final refinement to convergence on $F^{2}$ gave $R=0.0314$ ( $F, 2809$ obs. data only) and $R_{\mathrm{w}}=0.0788$ $\left(F^{2}\right.$, all data $), \mathrm{GOF}=1.066$.

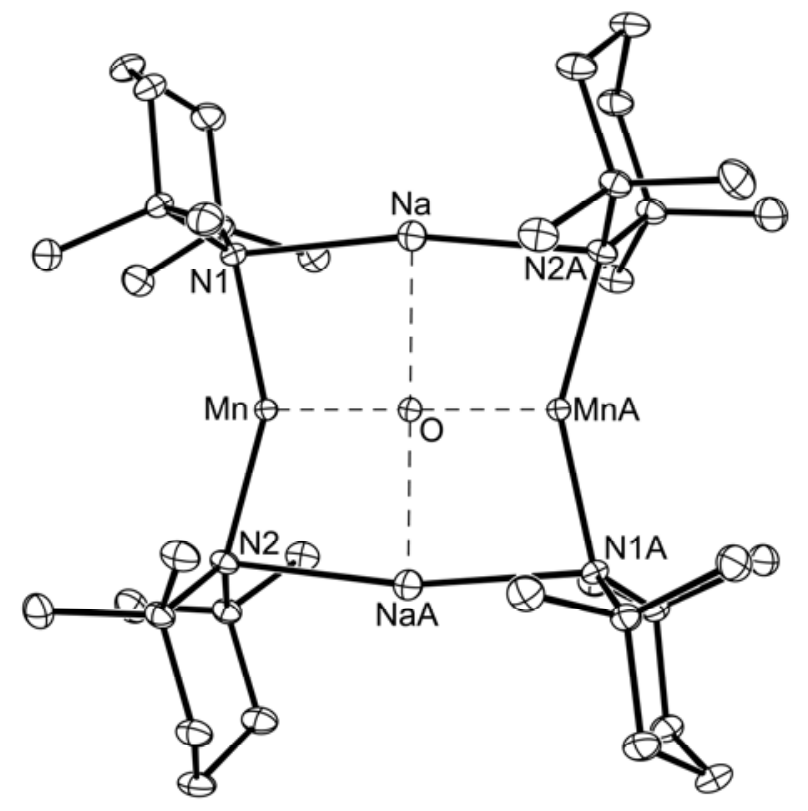

Figure S2. Molecular structure of 4 (on the 30\% probability level). Hydrogen atoms have been omitted for clarity. 
Crystal data for 6: $\mathrm{C}_{52.4} \mathrm{H}_{108} \mathrm{Mn}_{2} \mathrm{~N}_{8} \mathrm{Na}_{2}, M_{r}=1006.13 \mathrm{~g} / \mathrm{mol}$, monoclinic, space group $\mathrm{P} 2{ }_{1} / \mathrm{n}, a$ $=8.2875(3), b=21.6756(9), c=16.5068(7) \AA, \beta=90.465(4){ }^{\circ}, V=2965.1(2) \AA^{3}, Z=2, \lambda=$ $0.71073 \AA, \mu=0.479 \mathrm{~mm}^{-1}, T=123 \mathrm{~K} ; 35537$ reflections, 7821 unique, $R_{\text {int }} 0.0389$; final refinement to convergence on $F^{2}$ gave $R=0.0549$ ( $F, 5597$ obs. data only) and $R_{\mathrm{w}}=0.1424$ $\left(F^{2}\right.$, all data $), \mathrm{GOF}=1.072$.

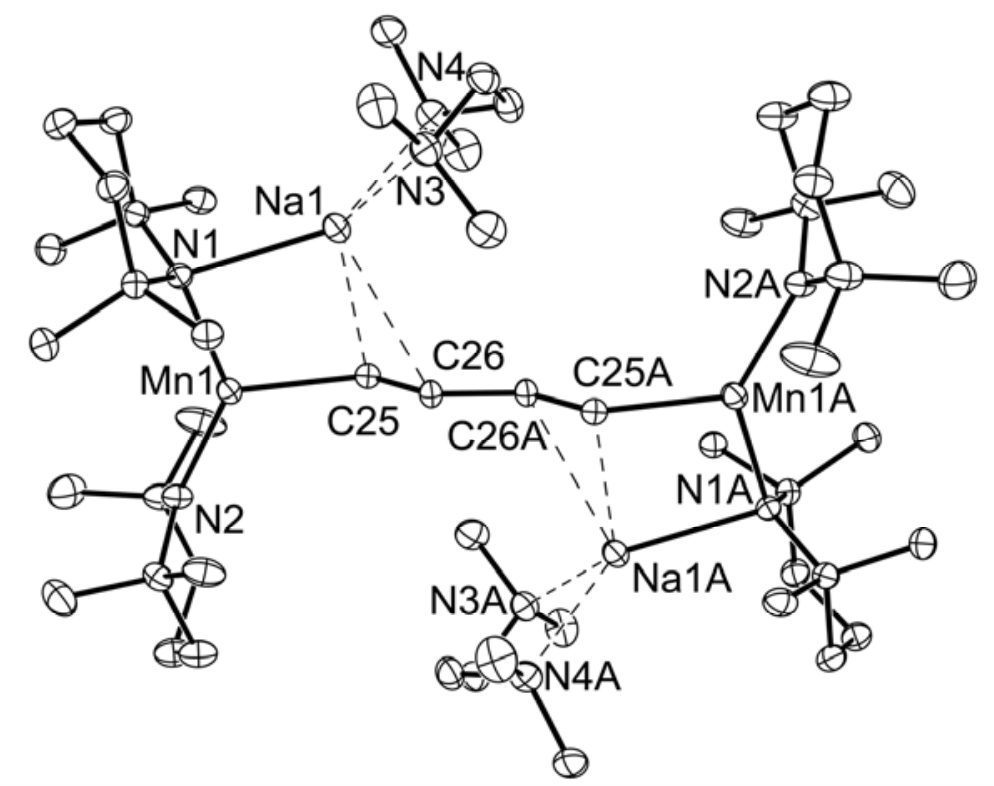

Figure S3. Molecular structure of 6 (on the 30\% probability level). Hydrogen atoms and minor disorder have been omitted for clarity. 


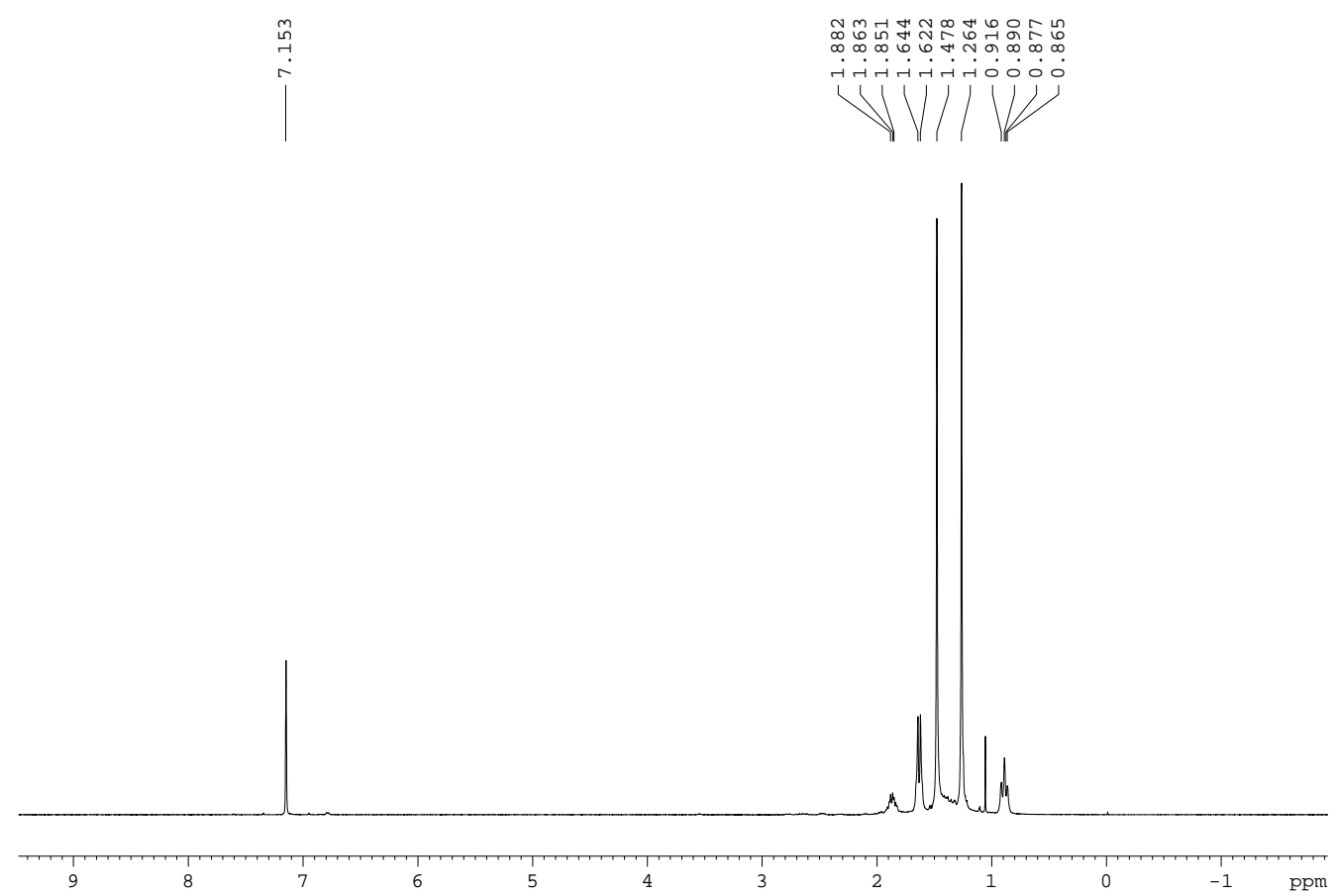

Figure S4. ${ }^{1} \mathrm{H}$ NMR spectrum of $\left[\mathrm{Na}_{2} \mathrm{Mg}_{2}(\mathrm{TMP})_{4}(\mathrm{O})\right], 3$ in $\mathrm{d}_{6}$-benzene.
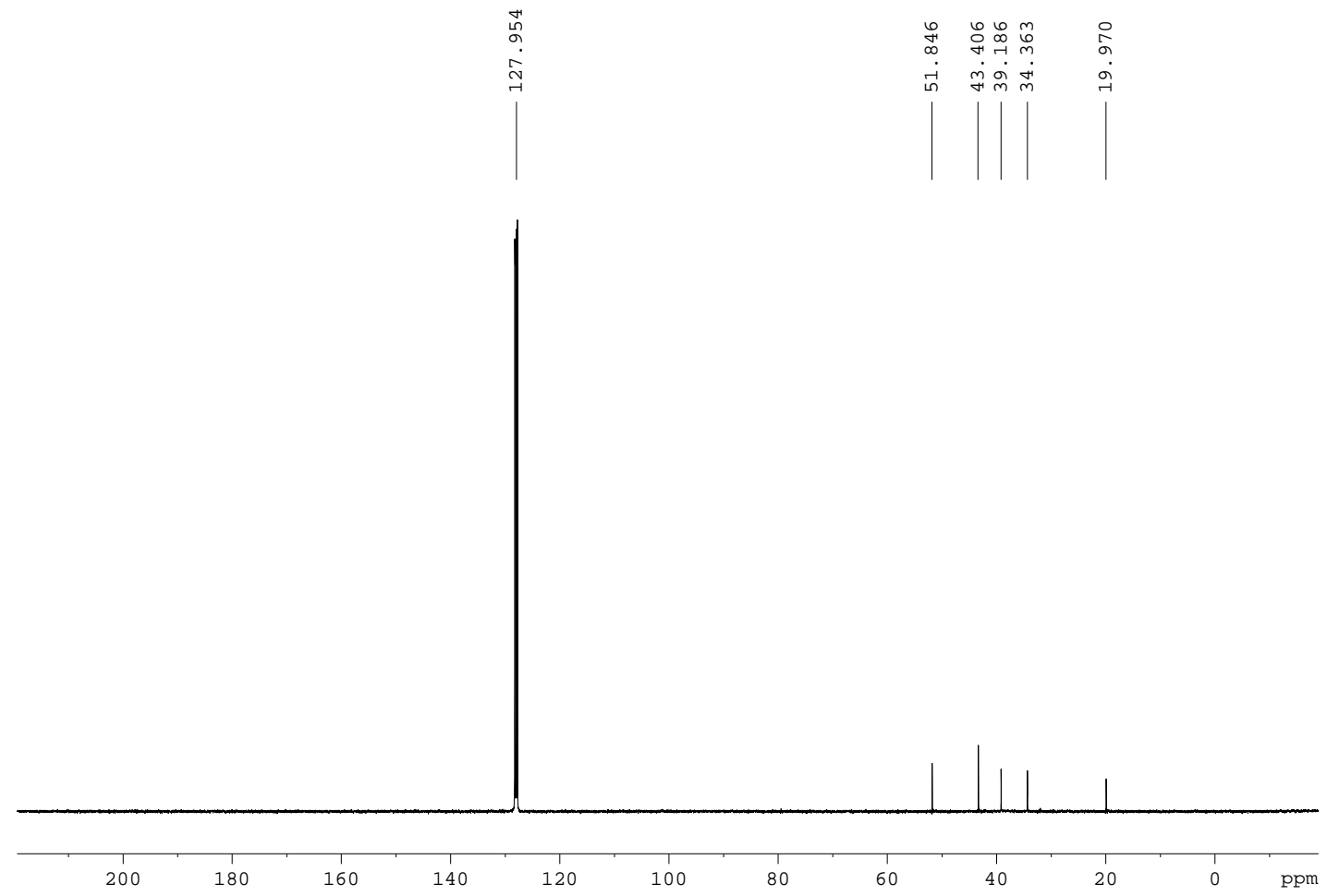

Figure S5. ${ }^{13} \mathrm{C}$ NMR spectrum of $\left[\mathrm{Na}_{2} \mathrm{Mg}_{2}(\mathrm{TMP})_{4}(\mathrm{O})\right], 3$ in $\mathrm{d}_{6}$-benzene. 


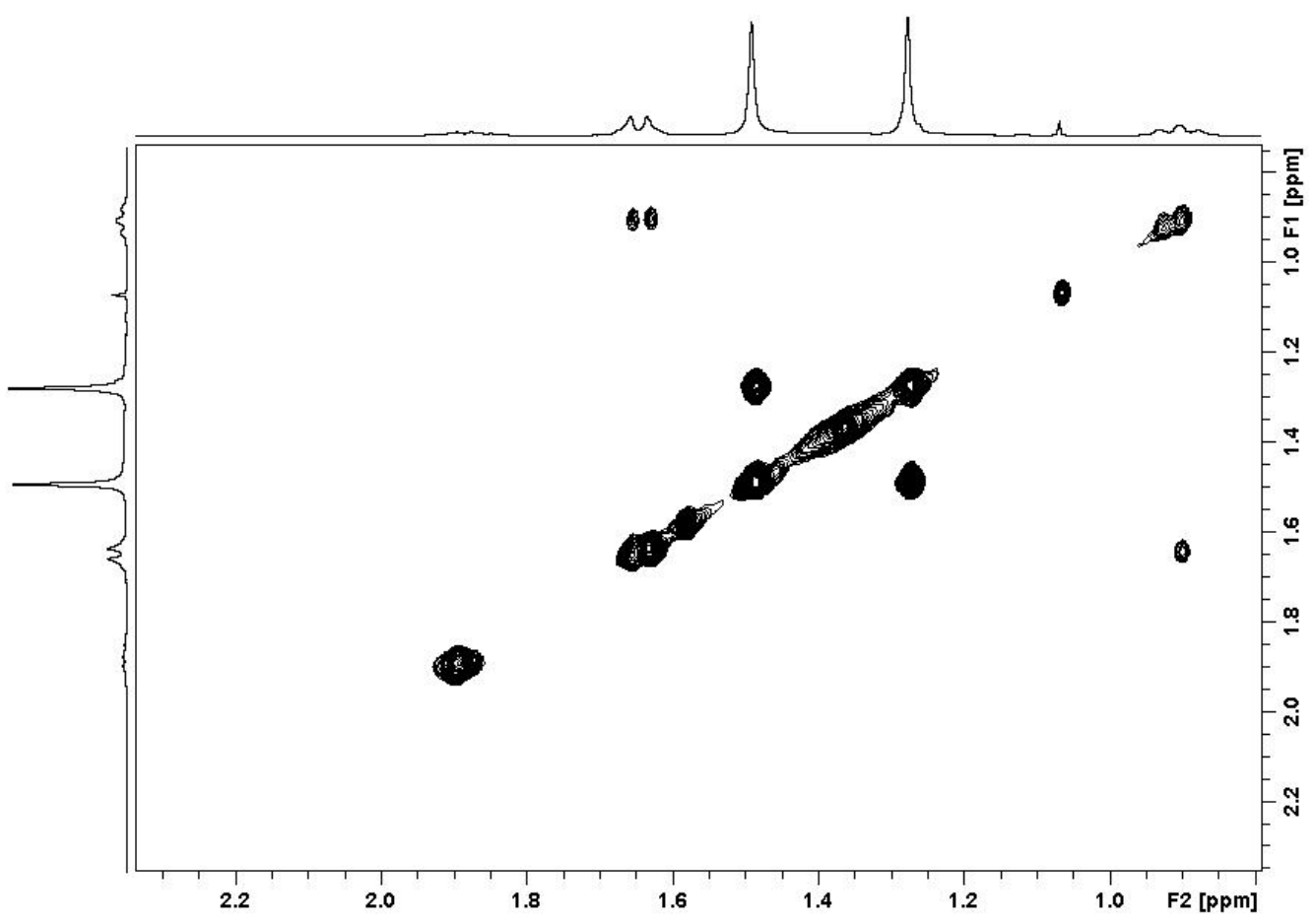

Figure S6. ${ }^{1} \mathrm{H}$ EXSY NMR spectrum of $\left[\mathrm{Na}_{2} \mathrm{Mg}_{2}(\mathrm{TMP})_{4}(\mathrm{O})\right], 3$ in $\mathrm{d}_{6}$-benzene.

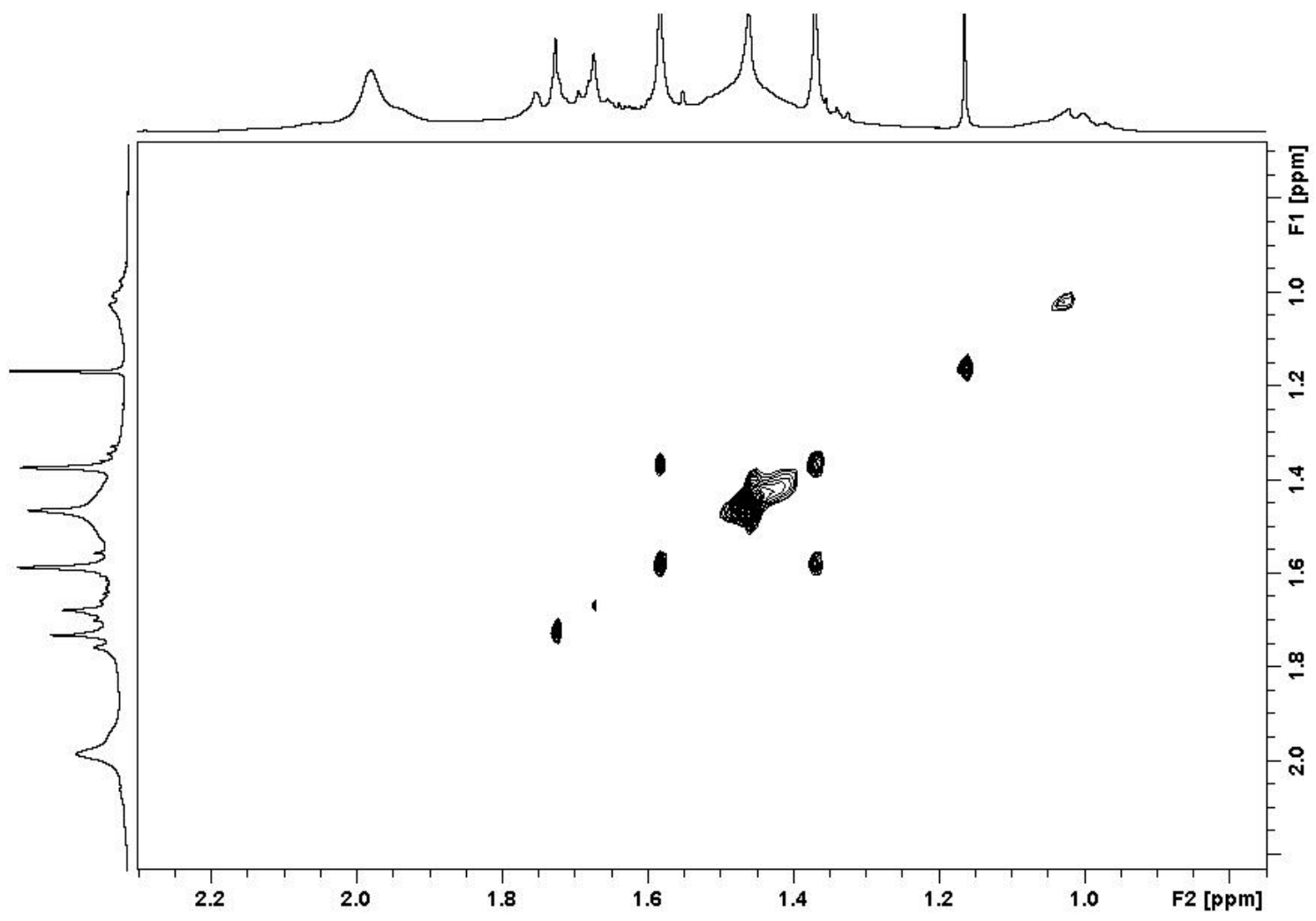

Figure S7. ${ }^{1} \mathrm{H}$ NOESY NMR spectrum of $\left[\mathrm{Na}_{2} \mathrm{Mg}_{2}(\mathrm{TMP})_{4}(\mathrm{O})\right], 3$ in $\mathrm{d}_{6}$-benzene. 


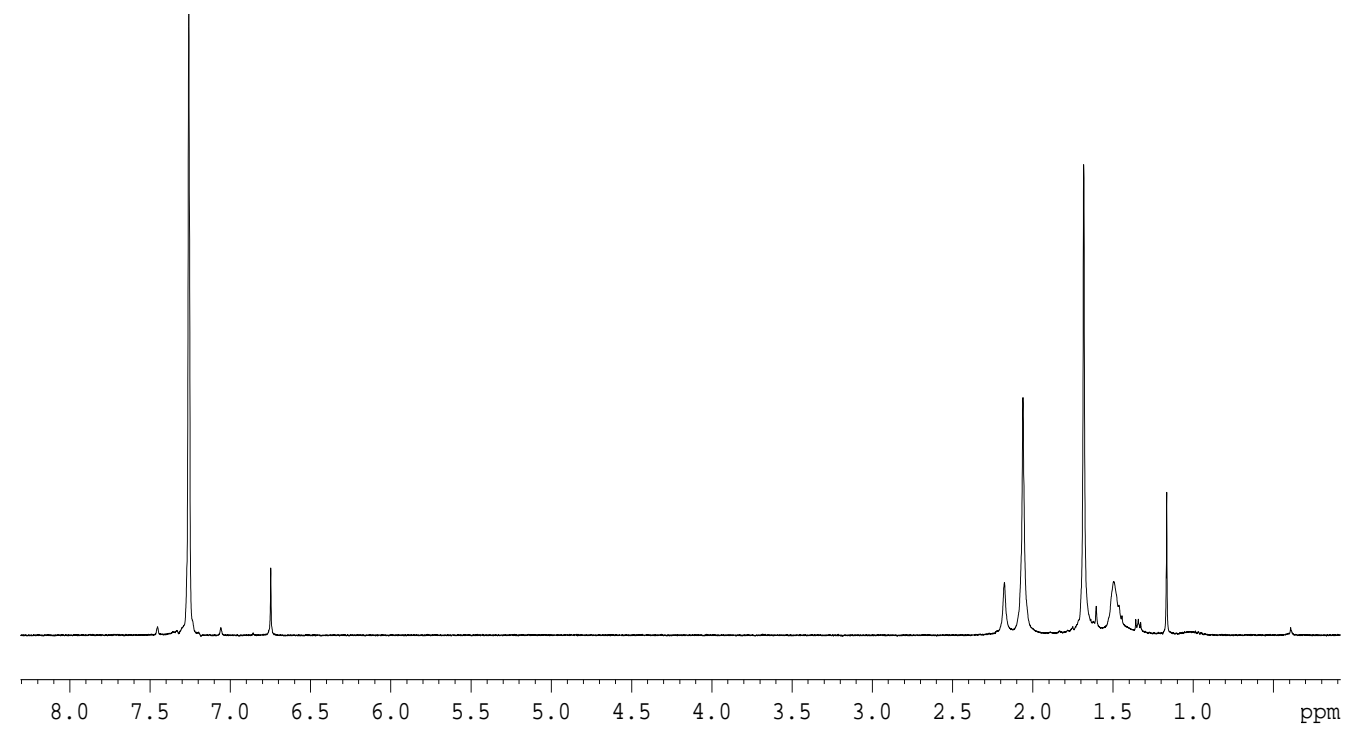

Figure S8. ${ }^{1} \mathrm{H}$ NMR spectrum of [ $\left.\{(\mathrm{TMEDA}) \mathrm{Na}(\mu-\mathrm{TMP})\}_{2}\left\{1,4-[\mathrm{Mg}(\mathrm{TMP})]_{2}-\mathrm{C}_{4} \mathrm{H}_{4}\right\}\right], 5$ in $\mathrm{d}_{6}$ benzene.

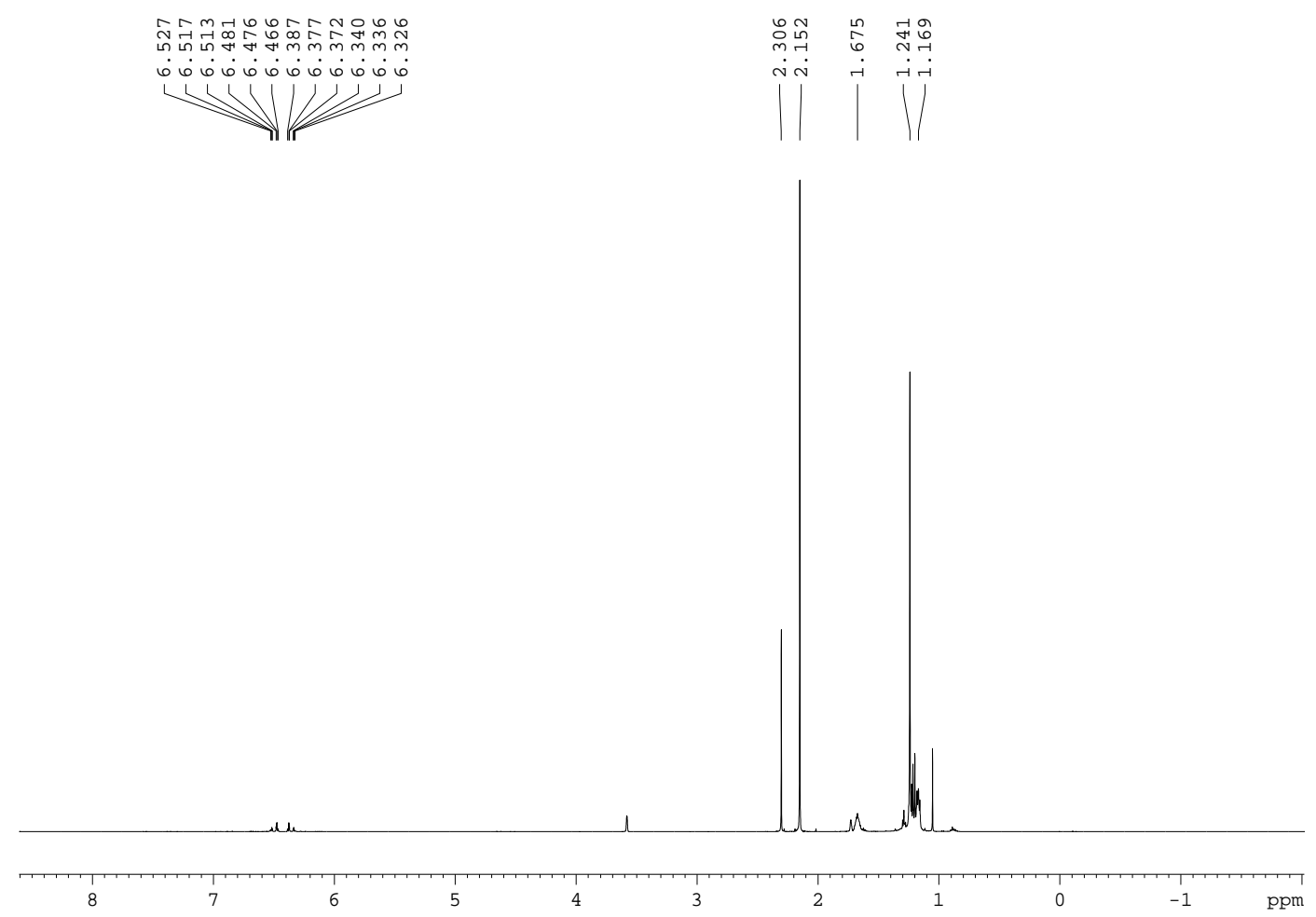

Figure S9. ${ }^{1} \mathrm{H}$ NMR spectrum of $\left[\{(\text { TMEDA }) \mathrm{Na}(\mu-\mathrm{TMP})\}_{2}\left\{1,4-[\mathrm{Mg}(\mathrm{TMP})]_{2}-\mathrm{C}_{4} \mathrm{H}_{4}\right\}\right], \mathbf{5}$ in $\mathrm{d}_{8}-$ THF. 


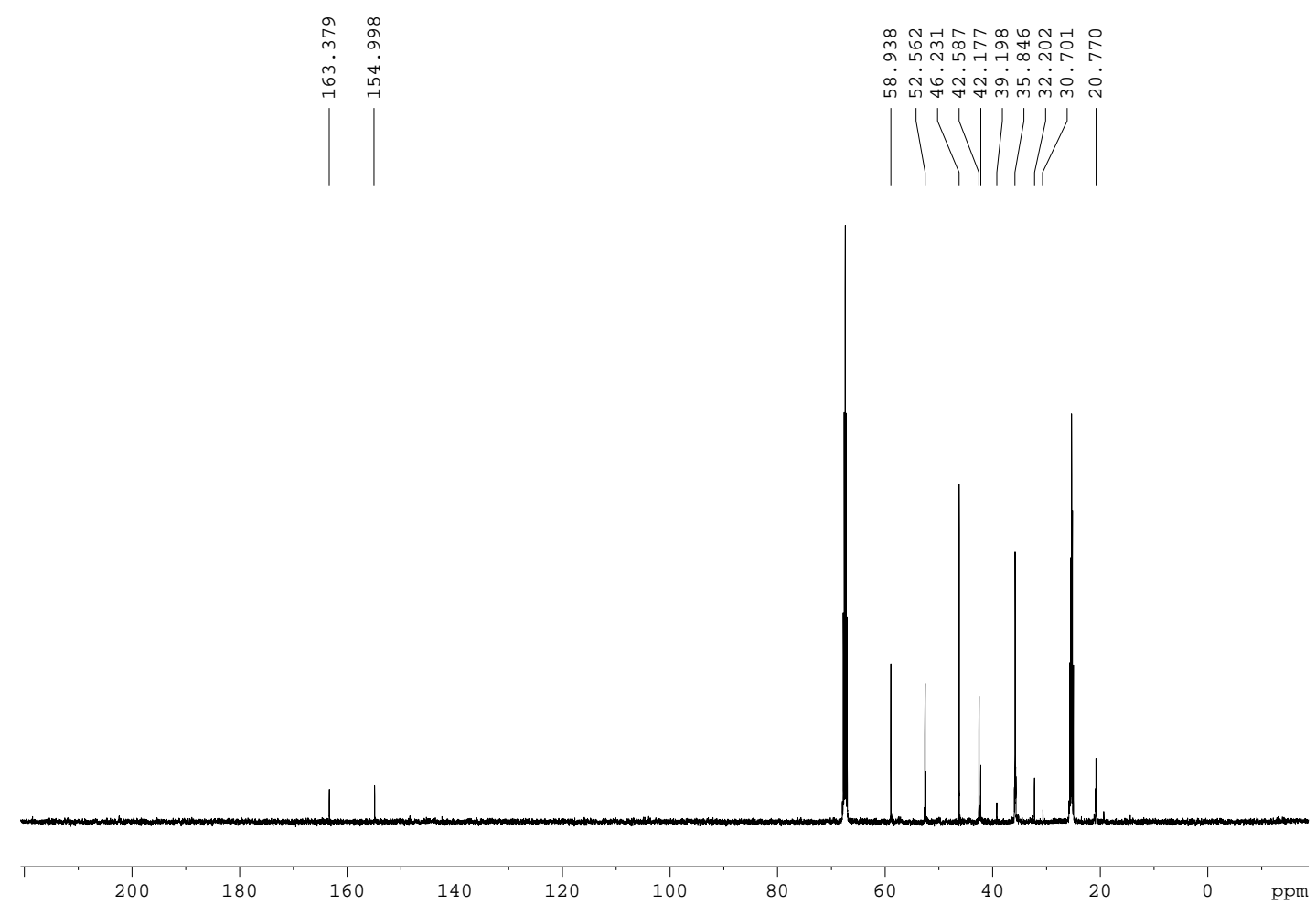

Figure S10. ${ }^{13} \mathrm{C}$ NMR spectrum of $\left[\{(\text { TMEDA }) \mathrm{Na}(\mu-\mathrm{TMP})\}_{2}\left\{1,4-[\mathrm{Mg}(\mathrm{TMP})]_{2}-\mathrm{C}_{4} \mathrm{H}_{4}\right\}\right], 5$ in $\mathrm{d}_{8}$-THF.

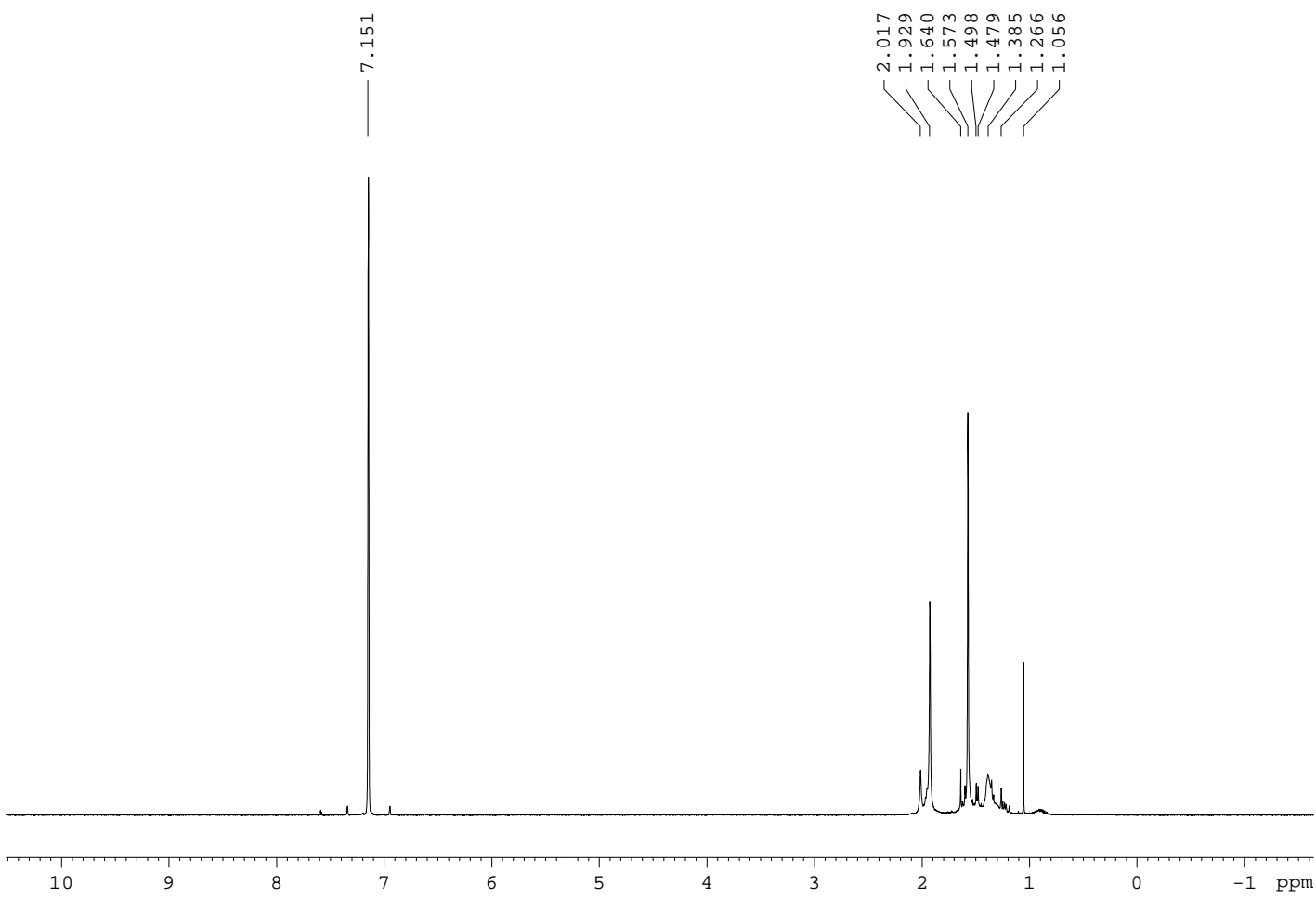

Figure S11. ${ }^{1} \mathrm{H}$ NMR spectrum of $\left[\{(\mathrm{TMEDA}) \mathrm{Na}(\mu-\mathrm{TMP})\}_{2}\left\{1,4-[\mathrm{Mg}(\mathrm{TMP})]_{2}-\mathrm{C}_{4} \mathrm{D}_{4}\right\}\right], \mathbf{5}\left(\mathbf{d}^{\mathbf{4}}\right)$ in $\mathrm{d}_{6}$-benzene. 

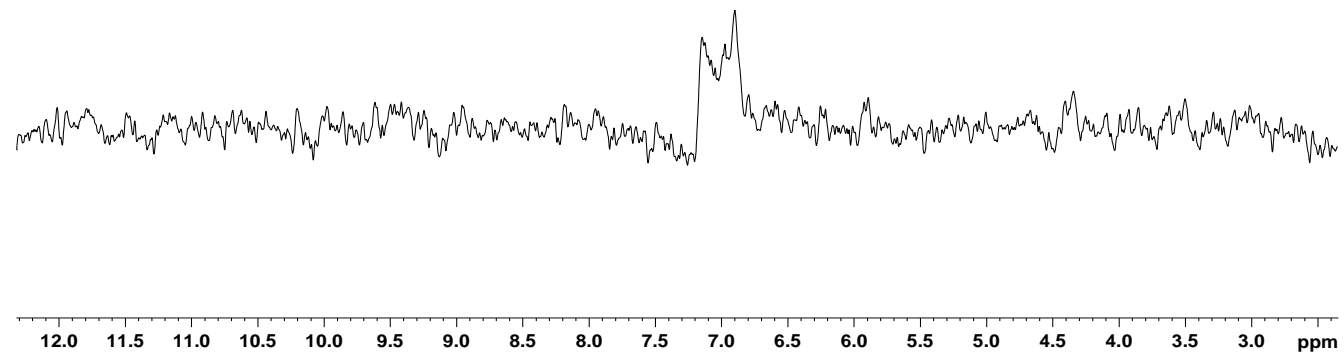

Figure S12. ${ }^{2} \mathrm{H}$ NMR spectrum of $\left[\{(\mathrm{TMEDA}) \mathrm{Na}(\mu-\mathrm{TMP})\}_{2}\left\{1,4-[\mathrm{Mg}(\mathrm{TMP})]_{2}-\mathrm{C}_{4} \mathrm{D}_{4}\right\}\right], \mathbf{5}\left(\mathbf{d}^{\mathbf{4}}\right)$ in benzene.

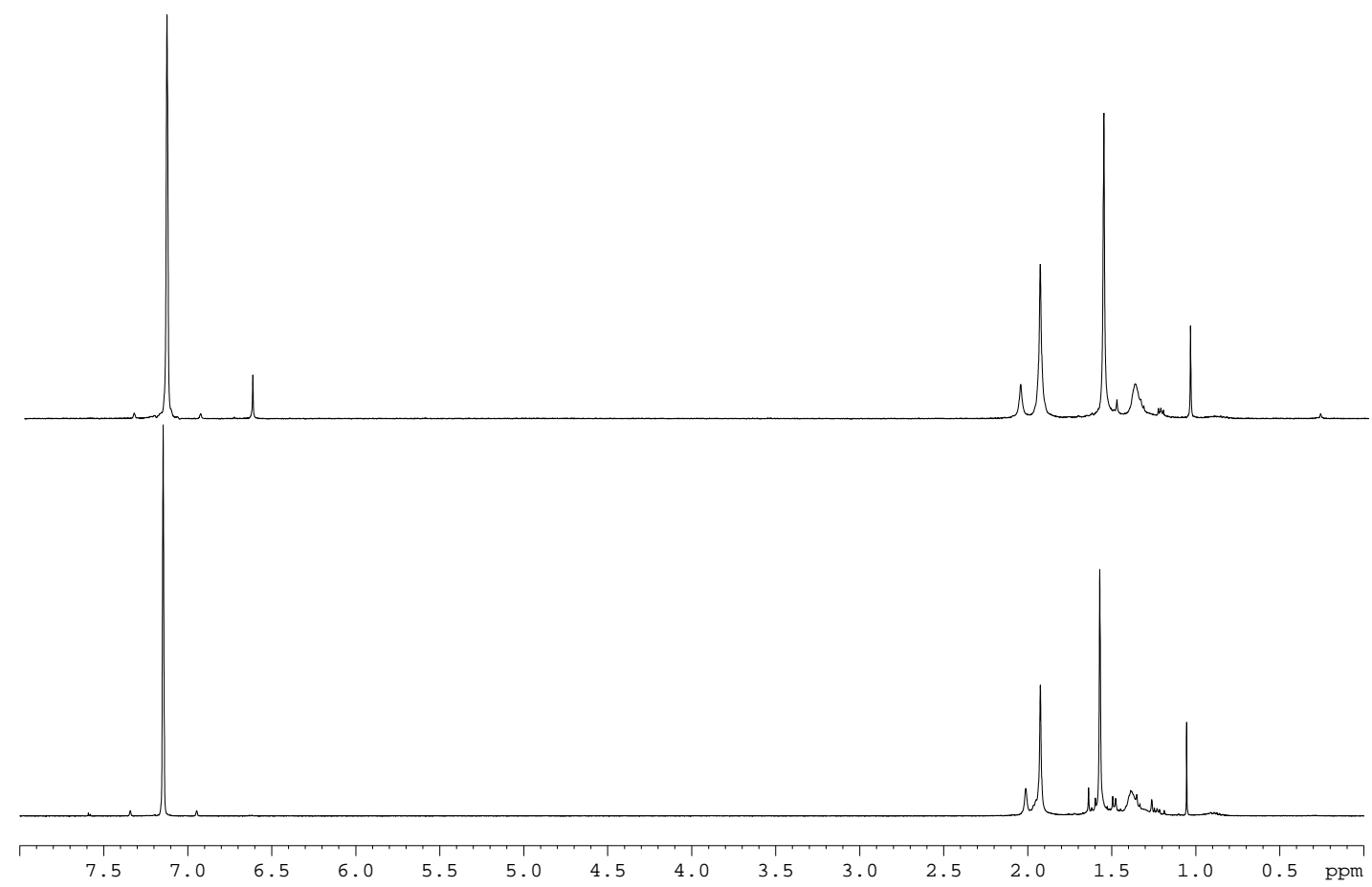

Figure S13. Comparison of ${ }^{1} \mathrm{H}$ NMR spectra of $\left[\{(\mathrm{TMEDA}) \mathrm{Na}(\mu-\mathrm{TMP})\}_{2}\left\{1,4-[\mathrm{Mg}(\mathrm{TMP})]_{2^{-}}\right.\right.$ $\left.\left.\mathrm{C}_{4} \mathrm{H}_{4}\right\}\right], 5$ (upper spectrum) and [\{(TMEDA)Na( $\left.\left.\left.\mu-\mathrm{TMP}\right)\right\}_{2}\left\{1,4-[\mathrm{Mg}(\mathrm{TMP})]_{2}-\mathrm{C}_{4} \mathrm{D}_{4}\right\}\right], \mathbf{5}\left(\mathbf{d}^{\mathbf{4}}\right)$ (lower spectrum) in $\mathrm{d}_{6}$-benzene. 


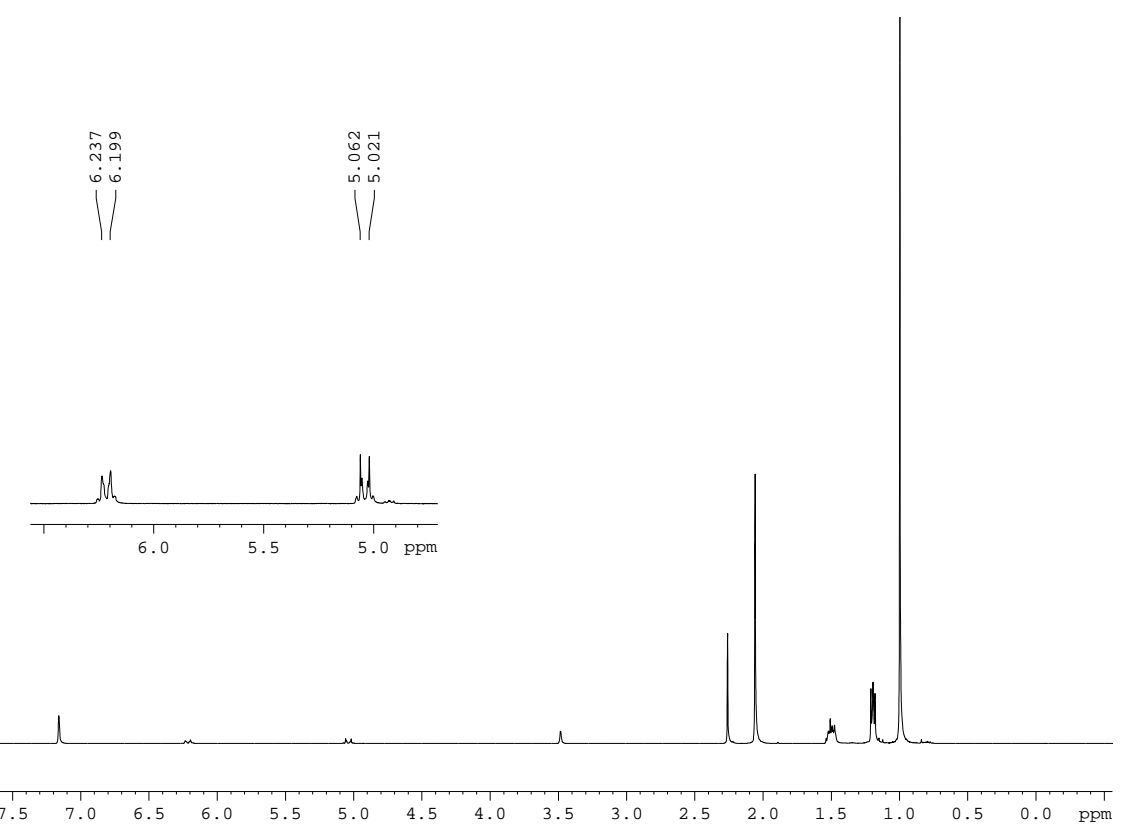

Figure S14. ${ }^{1} \mathrm{H}$ NMR spectrum of $\left[\{(\mathrm{TMEDA}) \mathrm{Na}(\mu-\mathrm{TMP})\}_{2}\left\{1,4-[\mathrm{Mg}(\mathrm{TMP})]_{2}-\mathrm{C}_{4} \mathrm{H}_{4}\right\}\right], 5$, hydrolysed with $\mathrm{D}_{2} \mathrm{O}$ to produce $\mathrm{C}_{4} \mathrm{H}_{4} \mathrm{D}_{2}$ in $\mathrm{d}_{6}$-benzene.

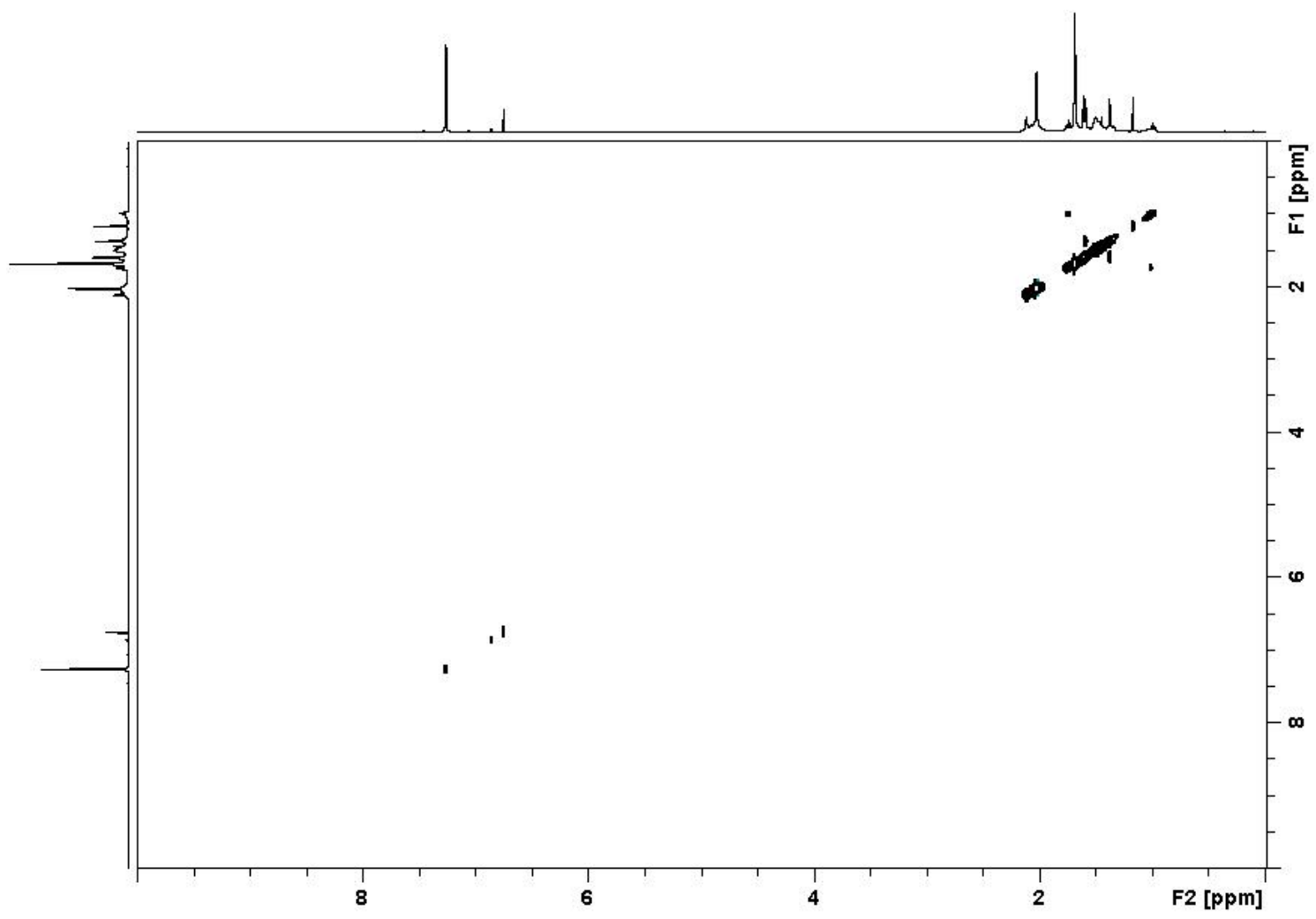

Figure S15. ${ }^{1} \mathrm{H}$ EXSY NMR spectrum of $\left[\{(\mathrm{TMEDA}) \mathrm{Na}(\mu-\mathrm{TMP})\}_{2}\left\{1,4-[\mathrm{Mg}(\mathrm{TMP})]_{2}-\right.\right.$ $\left.\mathrm{C}_{4} \mathrm{H}_{4}\right\}$ ], 5 in $\mathrm{d}_{6}$-benzene. 


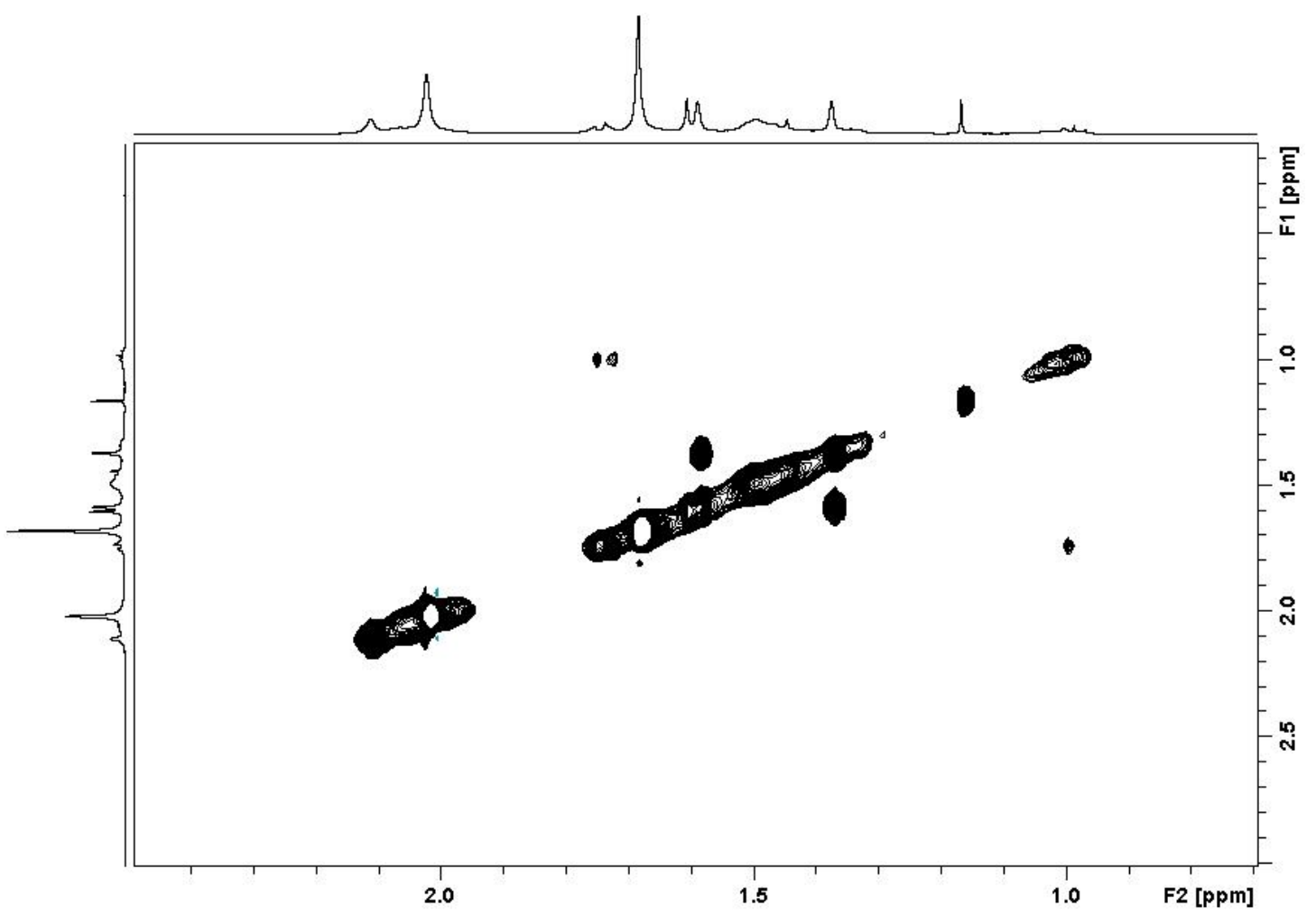

Figure S16. ${ }^{1} \mathrm{H}$ EXSY NMR spectrum of $\left[\{(\mathrm{TMEDA}) \mathrm{Na}(\mu-\mathrm{TMP})\}_{2}\left\{1,4-[\mathrm{Mg}(\mathrm{TMP})]_{2}-\right.\right.$ $\left.\mathrm{C}_{4} \mathrm{H}_{4}\right\}$ ], 5 in $\mathrm{d}_{6}$-benzene, detail of the aliphatic region.

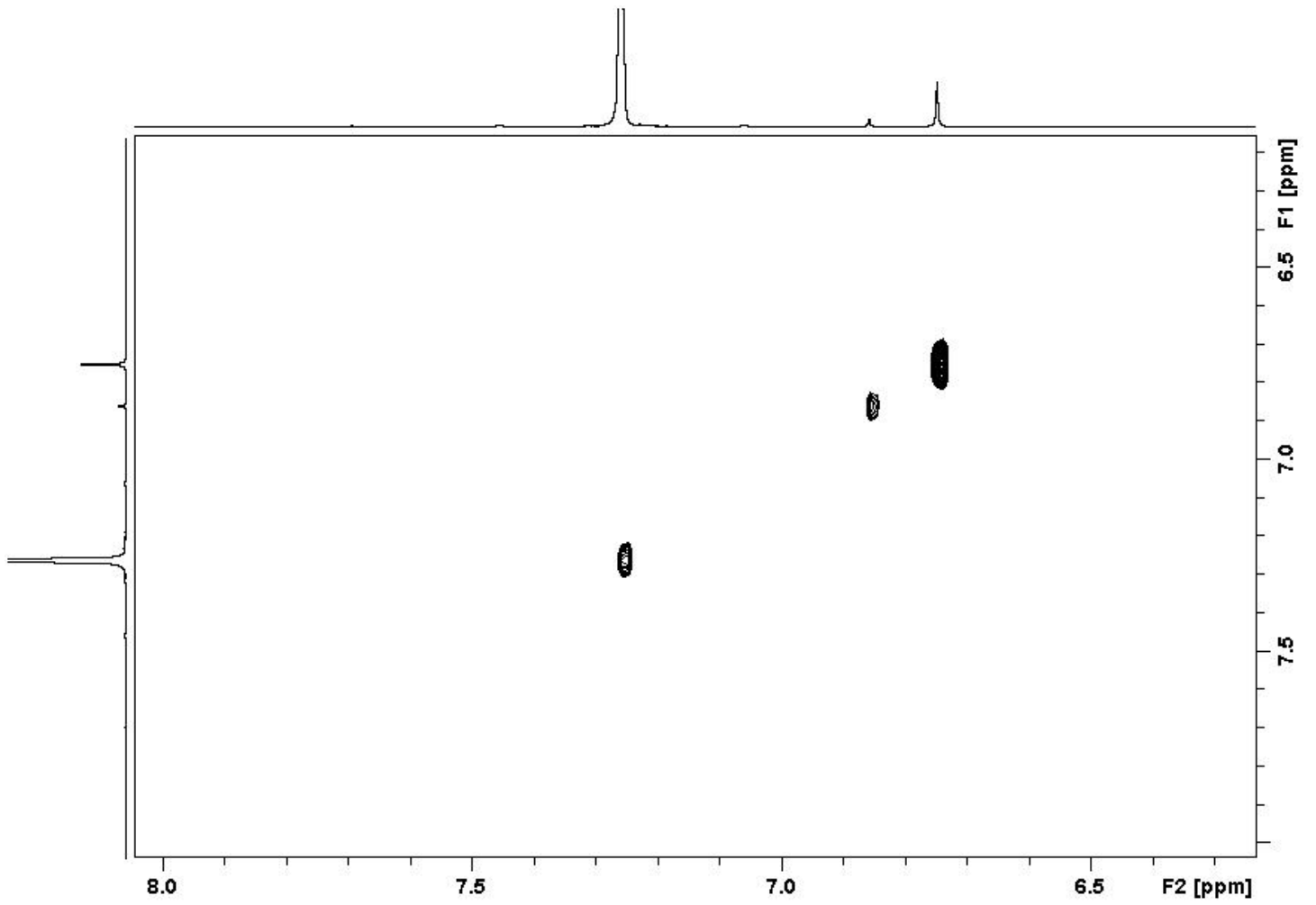

Figure S17. ${ }^{1} \mathrm{H}$ EXSY NMR spectrum of $\left[\{(\text { TMEDA }) \mathrm{Na}(\mu-\mathrm{TMP})\}_{2}\left\{1,4-[\mathrm{Mg}(\mathrm{TMP})]_{2}-\right.\right.$ $\left.\mathrm{C}_{4} \mathrm{H}_{4}\right\}$ ], 5 in $\mathrm{d}_{6}$-benzene, detail of the aromatic region. 


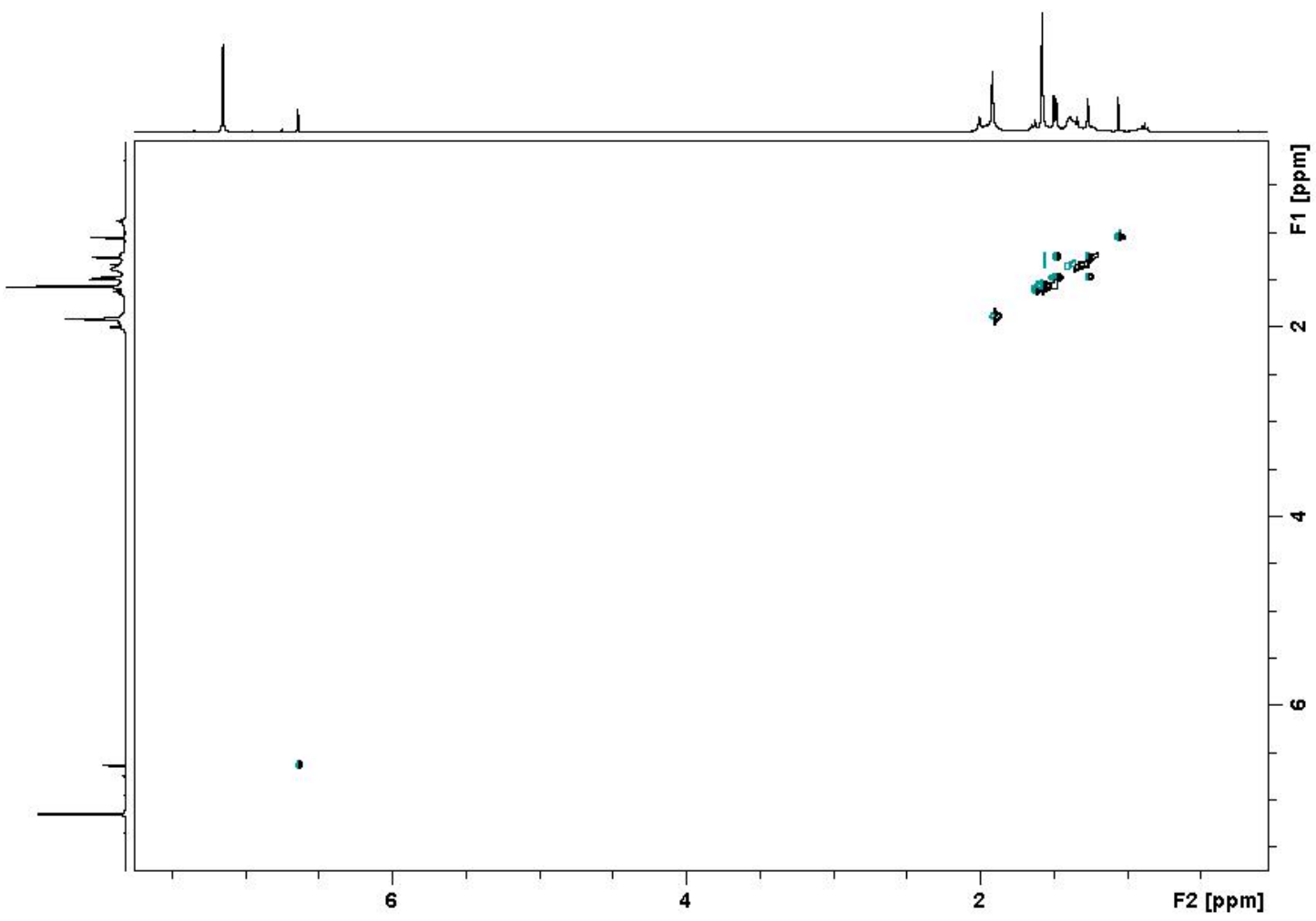

Figure S18. ${ }^{1} \mathrm{H}$ NOESY NMR spectrum of $\left[\{(\text { TMEDA }) \mathrm{Na}(\mu-\mathrm{TMP})\}_{2}\left\{1,4-[\mathrm{Mg}(\mathrm{TMP})]_{2}-\right.\right.$ $\left.\mathrm{C}_{4} \mathrm{H}_{4}\right\}$ ], 5 in $\mathrm{d}_{6}$-benzene.

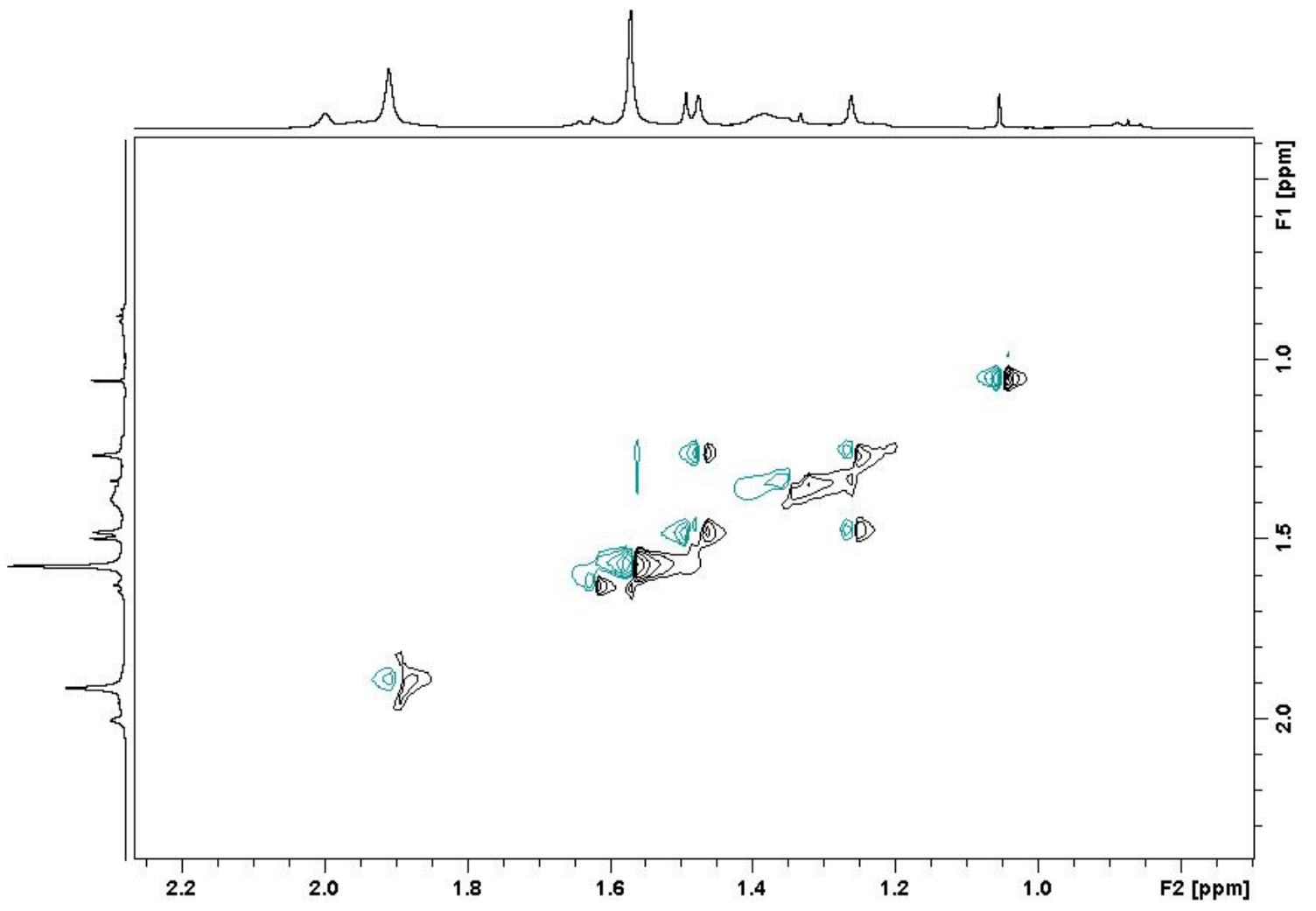

Figure S19. ${ }^{1} \mathrm{H}$ NOESY NMR spectrum of $\left[\{(\mathrm{TMEDA}) \mathrm{Na}(\mu-\mathrm{TMP})\}_{2}\left\{1,4-[\mathrm{Mg}(\mathrm{TMP})]_{2}-\right.\right.$ $\left.\mathrm{C}_{4} \mathrm{H}_{4}\right\}$ ], 5 in $\mathrm{d}_{6}$-benzene, detail of the aliphatic region. 


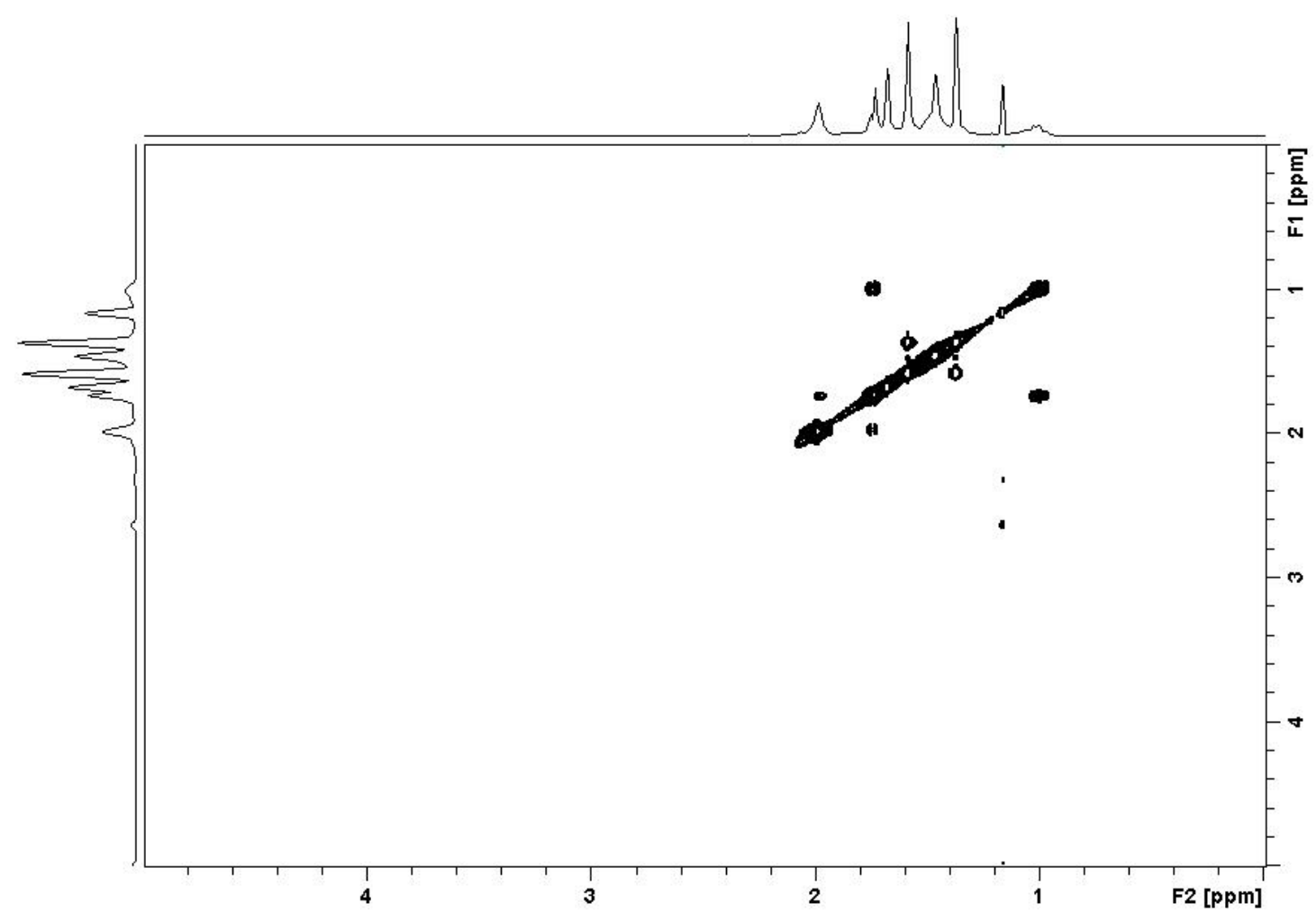

Figure S20. ${ }^{1} \mathrm{H}$ EXSY NMR spectrum of a mixture of $\left[\mathrm{Na}_{2} \mathrm{Mg}_{2}(\mathrm{TMP})_{4}(\mathrm{O})\right], 3$ and $\left[\{(\mathrm{TMEDA}) \mathrm{Na}(\mu-\mathrm{TMP})\}_{2}\left\{1,4-[\mathrm{Mg}(\mathrm{TMP})]_{2}-\mathrm{C}_{4} \mathrm{H}_{4}\right\}\right], 5$ in $\mathrm{d}_{6}$-benzene.

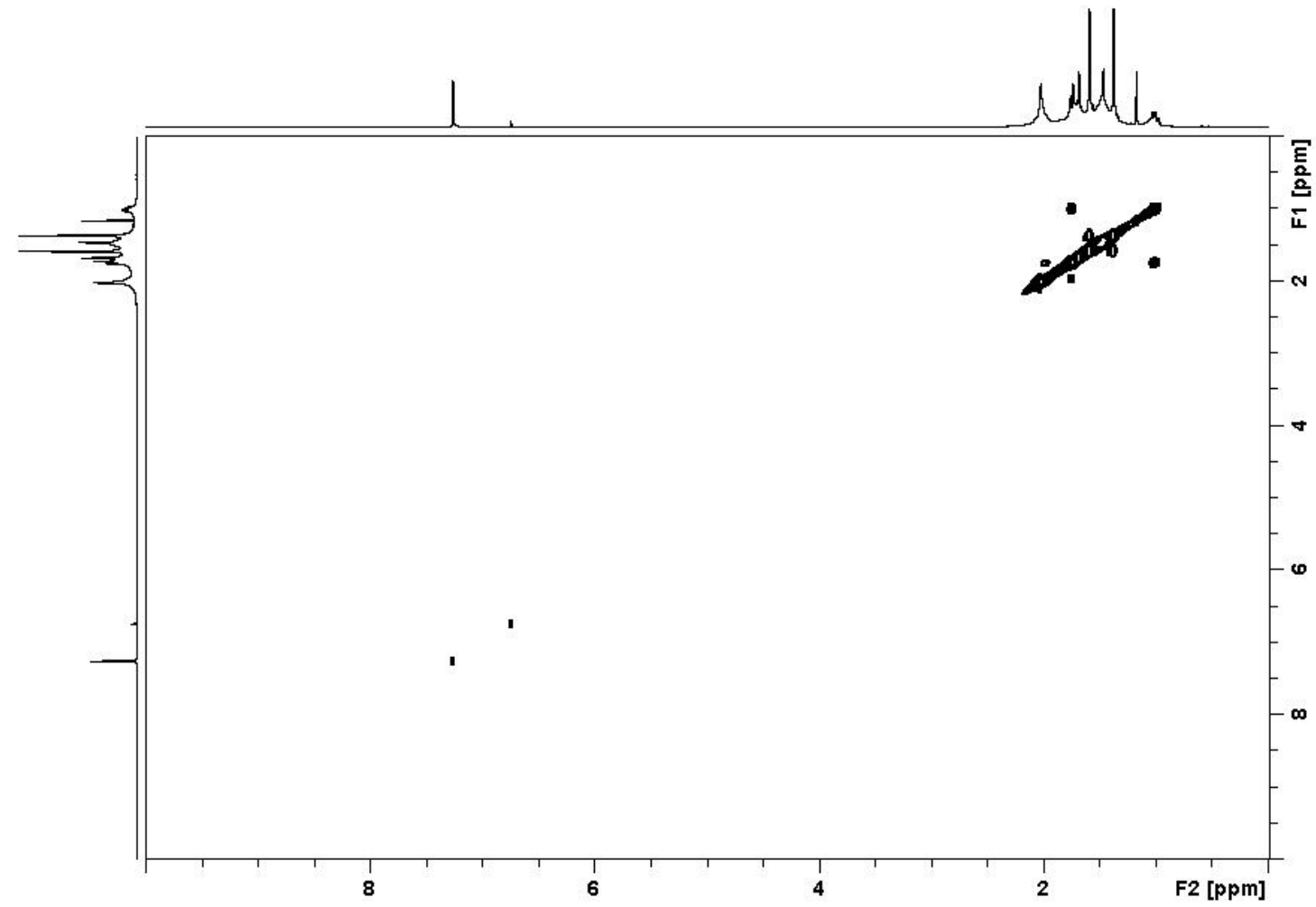

Figure S21. ${ }^{1} \mathrm{H}$ NOESY NMR spectrum of a mixture of $\left[\mathrm{Na}_{2} \mathrm{Mg}_{2}(\mathrm{TMP})_{4}(\mathrm{O})\right], 3$ and $\left[\{(\mathrm{TMEDA}) \mathrm{Na}(\mu-\mathrm{TMP})\}_{2}\left\{1,4-[\mathrm{Mg}(\mathrm{TMP})]_{2}-\mathrm{C}_{4} \mathrm{H}_{4}\right\}\right], 5$ in $\mathrm{d}_{6}$-benzene. 


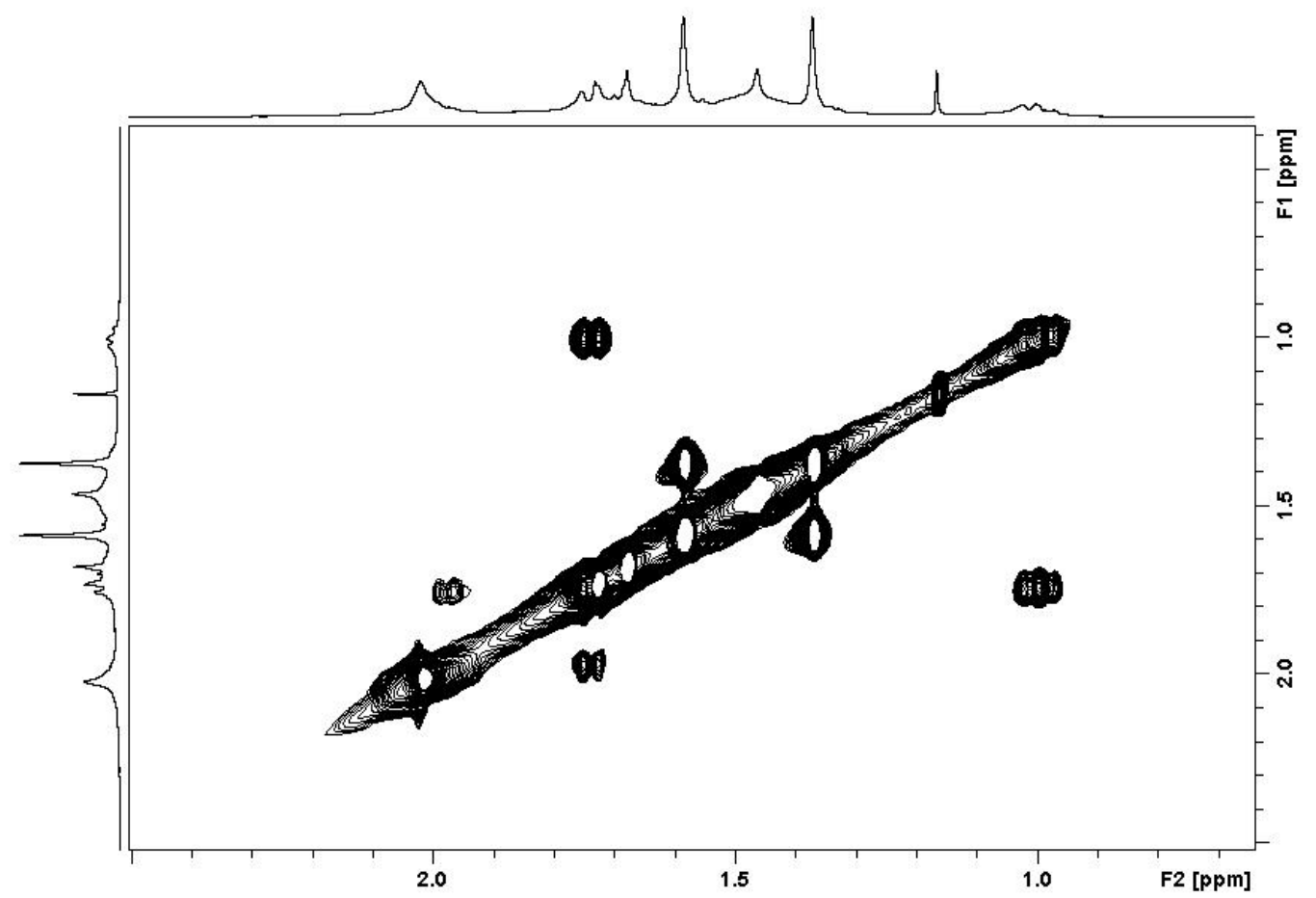

Figure S22. ${ }^{1} \mathrm{H}$ NOESY NMR spectrum of a mixture of $\left[\mathrm{Na}_{2} \mathrm{Mg}_{2}(\mathrm{TMP})_{4}(\mathrm{O})\right], 3$ and $\left[\{(\mathrm{TMEDA}) \mathrm{Na}(\mu-\mathrm{TMP})\}_{2}\left\{1,4-[\mathrm{Mg}(\mathrm{TMP})]_{2}-\mathrm{C}_{4} \mathrm{H}_{4}\right\}\right], 5$ in $\mathrm{d}_{6}$-benzene, detail of the aliphatic region.

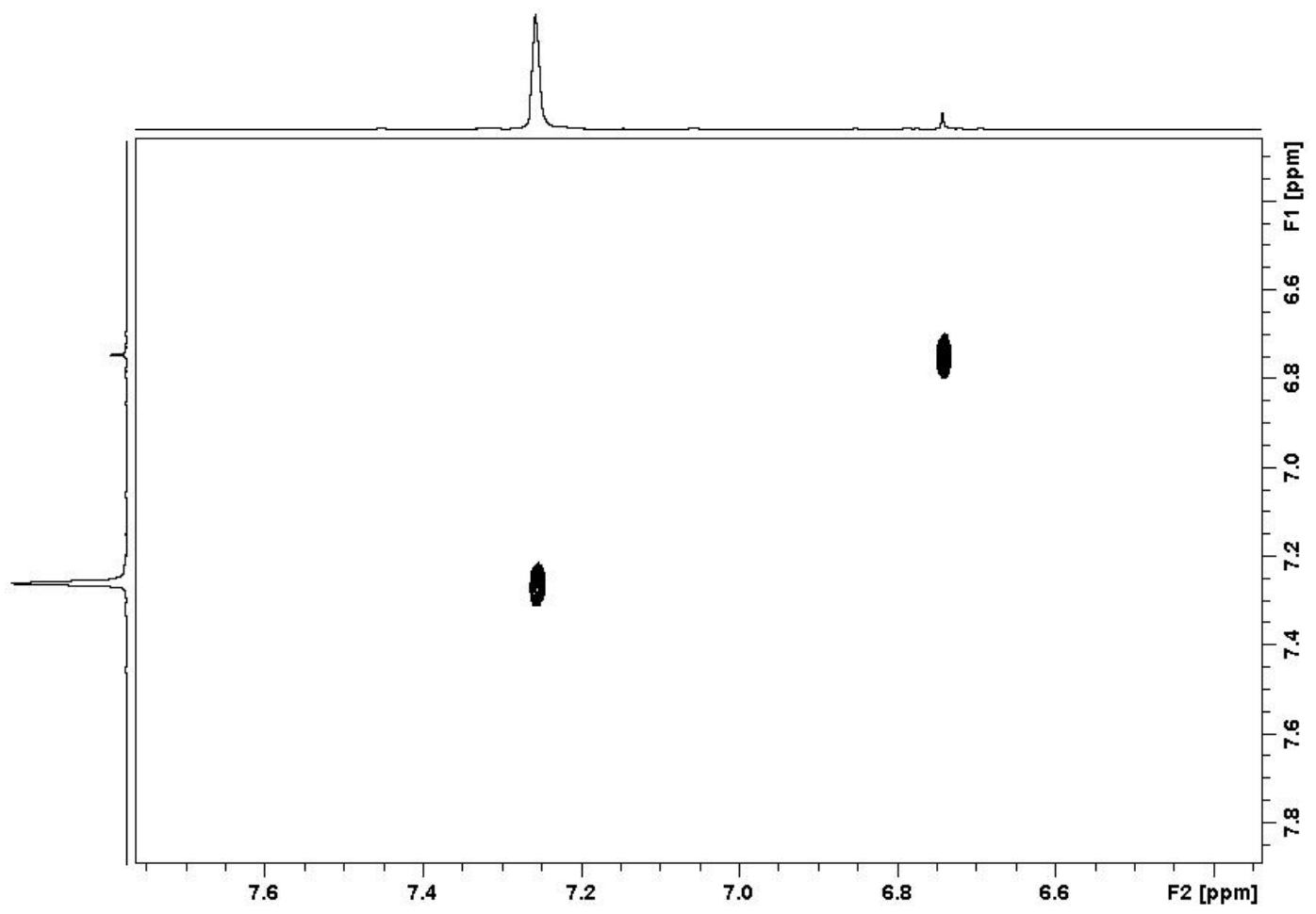

Figure S23. ${ }^{1} \mathrm{H}$ NOESY NMR spectrum of a mixture of $\left[\mathrm{Na}_{2} \mathrm{Mg}_{2}(\mathrm{TMP})_{4}(\mathrm{O})\right], 3$ and $\left[\{(\mathrm{TMEDA}) \mathrm{Na}(\mu-\mathrm{TMP})\}_{2}\left\{1,4-[\mathrm{Mg}(\mathrm{TMP})]_{2}-\mathrm{C}_{4} \mathrm{H}_{4}\right\}\right], 5$ in $\mathrm{d}_{6}$-benzene, detail of the aliphatic region. 


\section{References}

[1] Andersen, R. A. \& Wilkinson, G. Bis(neopentyl)-, bis(trimethylsilylmethyl)- and bis(2methyl-2-phenylpropyl)-magnesium. J. Chem. Soc., Dalton Trans. 809-811 (1977).

[2] Andersen, R. A., Carmona-Guzman, E., Gibson, J. F. \& Wilkinson, G. Neopentyl, neophyl, and trimethylsilylmethyl compounds of manganese. Manganese(II) dialkyls; manganese(II) dialkyl amine adducts; tetra-alkylmanganate(II) ions and lithium salts; manganese(IV) tetra-alkyls. J. Chem. Soc., Dalton Trans. 2204-2211 (1976).

[3] Alberola, A. et al. Bis[(trimethylsilyl)methyl]manganese: Structural variations of its solvent-free and TMEDA-, pyridine-, and dioxane-complexed forms. Organometallics, 28, 2112-2118 (2009).

[4] Sheldrick, G. M. A short history of SHELX. Acta Cryst. A, 64, 112-122 (2008). 